Department of General, Visceral and Child Surgery

(Prof. Dr. med. B. M. Ghadimi)

Center for Surgery

Medical Faculty of the Georg-August University of Göttingen

\title{
Silencing of the Wnt transcription factor TCF4 sensitizes colorec- tal cancer cells to (chemo-) radiotherapy
}

\author{
INAUGURAL DISSERTATION \\ Doctoral Degree
}

at the

Medical Faculty

Georg University of Göttingen

submitted by

Emil Fritz Kendziorra

Born in Darmstadt on January, $18^{\text {th }} 1986$

Göttingen 2013 
Dean:

I. Reviewer:

II. Reviewer:

III. Reviewer:

Date of oral examination:
Prof. Dr. rer. nat. H. K. Kroemer

Prof. Dr. med. B. M. Ghadimi

Prof. Dr. C. Binder

Prof. Dr. M. Oppermann

07.10.2014 


\section{Table of content}

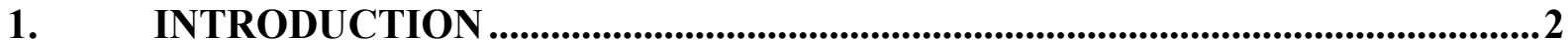

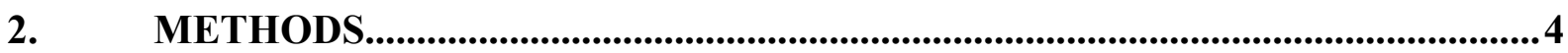

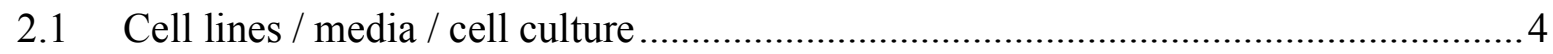

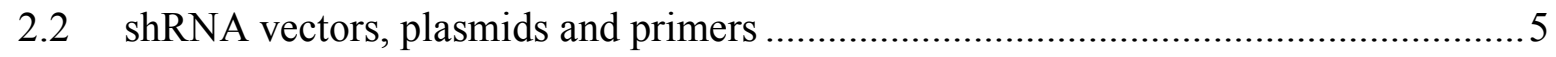

2.3 Transfection and establishment of stable cell clone populations .............................5

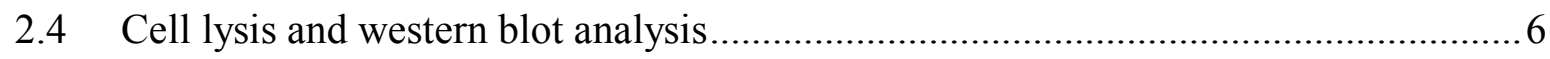

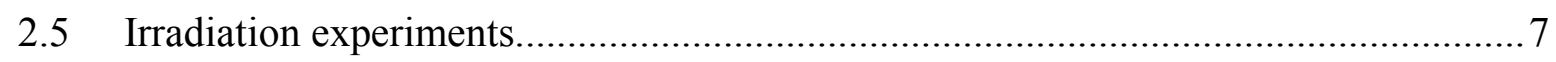

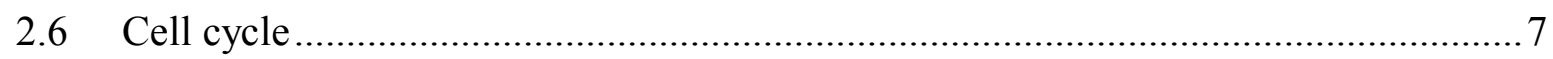

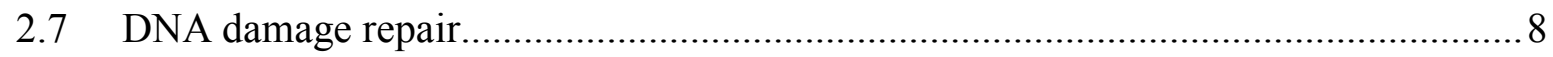

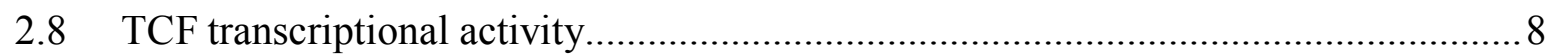

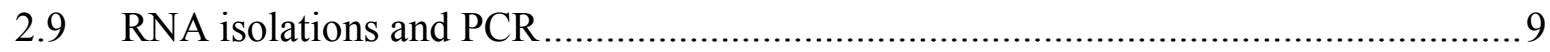

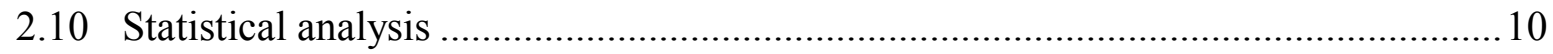

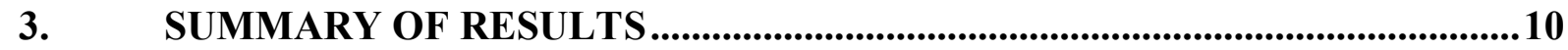

3.1 TCF7L2 expression is correlated to radioresistance .......................................... 10

3.2 Inhibition of TCF7L2 is associated with increased radiosensitivity ......................... 11

3.3 Impaired cell cycle control and reduced DNA damage repair increase sensitivity.... 14

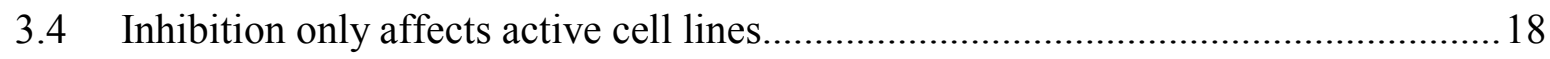

3.5 shTCF7L2 deregulates Wnt/TCF7L2 signaling ............................................ 19

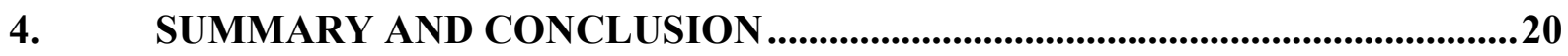

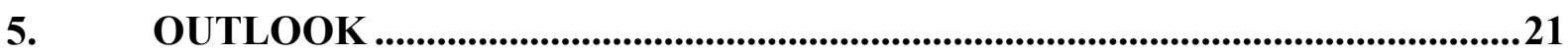

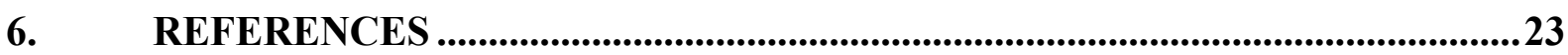

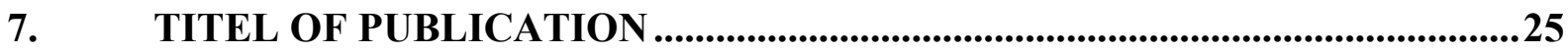




\section{INTRODUCTION}

Even though cancer has been one of the most funded research topics in the last decades, it is still one of the leading causes of death, second only to cardiovascular diseases (Howlader et al. 2012). Despite tremendous efforts to predict, treat, and cure cancer, a lot of questions remain unanswered and prognosis for certain types of cancer is still very poor.

Colorectal cancer represents one of the most important cancer entities, accounting for about 70.000 newly diagnosed cancer cases per year in Germany alone, leading the statistic before breast cancer (about 46.000) and lung cancer (about 37.000) as detailed in the "Gesundheitsbericht für Deutschland" published by the Robert Koch-Institut in Berlin, Germany. Colorectal cancer is also one of the leading causes of cancer-related death accounting for over 25.000 deaths in Germany each year. Most cases are of sporadic origin with only 5-10\% representing hereditary cancers (Lynch and de la Chapelle 2003). The median age of diagnosis lies between 60 and 70 years, with a steep increase in incidence after 50 years of age. As a consequence, regular colonoscopies are recommended from age 55 (for patients without additional risk factors) onward to detect developing carcinomas early and start treatment when the prognosis is still good. In general, risk factors for the development of colorectal cancer are age, gender (higher risk for males), alcohol, high caloric diet, raw meat, and a sedentary lifestyle.

Treatment decisions are based upon the tumor staging following the TNM classification ("T" depicts depth of invasion, "N" lymph node status, and "M" presence of distant metastasis) put forth by the UICC (Union for International Cancer Control, Sobin and Fleming 1997). This study focuses on locally advanced rectal cancer (UICC stage II/III).

The standard treatment for locally advanced rectal cancers consists of preoperative 5fluorouracil (5-FU)-based chemoradiotherapy followed by radical surgery. Preoperative chemoradiotherapy is employed to reduce tumor burden, improve resectability, and to increase the chance to completely resect the tumor. Furthermore, this multimodal approach re- 
duces local recurrence (Sauer et al. 2004). However, the clinical response to chemoradiotherapy varies greatly, and a considerable percentage of rectal cancers are "chemoradioresistant", meaning they are largely unaffected, even when intensified regimens of chemoradiotheray are being pursued (Cunningham et al. 2010). This represents a substantial clinical and socioeconomic problem. It is thus of utmost clinical importance to determine the molecular characteristics underlying this resistance and to identify effective strategies to overcome it (Kuremsky et al. 2009). Previously, we have therefore used gene expression profiling of resistant and responsive rectal cancers from patients who had been treated with preoperative chemoradiotherapy within a phase III clinical trial and identified a set of genes correlated with resistance. One of the genes that was identified as significantly overexpressed in resistant tumors was $\mathrm{T}$ cell factor 4 (TCF4, also, and more correctly named TCF7L2) (Ghadimi et al. 2005). TCF7L2 represents a key transcription factor that mediates canonical Wnt signaling, plays a central role in embryonic development and in the maintenance of tissue homeostasis (Clevers 2006, Klaus and Birchmeier 2008, Moon et al. 2004). In cells with an inactive canonical Wnt pathway, $\beta$-catenin, the main cofactor of TCF7L2 and required for transcription activity, is degraded by the so-called "destruction complex". This complex mainly consists of the scaffold protein Axin, which binds two other key components, Adenomatous Polyposis Coli (APC) and Glycogen Synthase Kinase-3 (GSK-3) (Clevers 2006). Binding of Wnt ligands to cell surface receptors of the Frizzled family inhibits glycogen-synthase-kinase-3 $\beta$-mediated phosphorylation of $\beta$-catenin, and subsequently halts its degradation, leading to the stabilization of $\beta$-catenin and its accumulation in the nucleus. This results in binding of $\beta$-catenin to members of the TCF and lymphoid enhancer-binding factor family of transcription factors, which then induces or represses transcription of a plethora of target genes (Nusse 1999). For example, cMyc, one of the most famous oncogenes, is regulated by TCF7L2 signaling as well as several cell cycle genes (e.g. CCND1) and genes involved in apoptosis and cellular survival pathways (e.g. survivin). A comprehensive list of target genes and in-depth information about the 
Wnt pathway can be found on the "Wnt homepage" (http://www.stanford.edu/group/nusselab/cgi-bin/wnt/), one of the best resources for information about the Wnt signaling pathway.

Furthermore, in the multistep carcinogenesis of colorectal cancers, deregulation of the Wnt pathway represents one of the main steps. During cancer development the APC gene (Adenomatous Polyposis Coli), which usually inhibits Wnt signaling as part of the destruction complex, is commonly mutated and the pathway is constitutively active, leading to an uncontrolled activation of transcription (Markowitz and Bertagnolli 2009). Other studies have shown that aberrant Wnt signaling promotes colorectal cancer (CRC) development (Clevers 2006, Klaus and Birchmeier 2008, Moon et al. 2004). Despite these studies, the Wnt signaling pathway has not yet been associated with treatment resistance of rectal cancer to chemoradiotheray. In this study, we therefore tested whether the observed overexpression of TCF7L2 is of functional relevance for mediating chemoradioresistance in rectal cancer.

\section{METHODS}

\subsection{Cell lines / media / cell culture}

Eight human colorectal cancer cell lines were included in this study (Caco-2, HT-29, SW1116, SW1463, SW480, SW620, SW837 and WiDr). All cell lines were cultured in their ATCC-recommended media, supplemented with fetal bovine serum and glutamine. No antibiotics were used except for selection of stably transfected clones. During culture cells were kept at around 60\% confluence (log-phase growth), subcultured at least twice a week, and media were regularly renewed. Furthermore, cells were regularly tested for mycoplasma infection by polymerase chain reaction (PCR). Functional experiments were performed in SW480, SW837 and HT-29. 


\subsection{ShRNA vectors, plasmids and primers}

RNAi-mediated silencing of TCF7L2 was performed using two different short-hairpin constructs (shRNA) for each of the three cell lines. A scrambled shRNA construct served as control (negative control, shNeg). Bacterial stocks were obtained from OpenBiosystems (pGIPZ lentiviral vector, ThermoFisher Scientific, Huntsville, AL), grown according to the manufacturer's manual, and vector DNA was extracted using the Endotoxin-free Maxi Prep extraction Kit from Qiagen (Hilden, Germany). Vector DNA was tested for proper extraction using restriction digestion with the Sal1 restriction endonuclease (New England Biolabs, Ipswich, MA, USA). Before transfection, vector DNA was linearized using Fsp1 (New England Biolabs) (unique restriction site) and purified to ensure optimal transfection conditions. The shRNA vectors contain a puromycin selection cassette and a GFP cassette which was used for selection and determination of transfection efficiency, respectively. All other vectors (TOPFLASH, FOPFLASH, CMV-renilla, S33Y- $\beta$-catenin) were used in a similar way, but were not linearized. Primers were designed as exon-spanning to ensure specificity for RNA molecules.

\subsection{Transfection and establishment of stable cell clone populations}

All cell lines were transfected using the Amaxa Nucleofection technique (Lonza, Cologne, Germany), comprising of a proprietary lipid solution combined with a proprietary electroporation method as detailed in the manufacturer's manual. In test experiments, the following transfection protocol and parameters were established to be most effective: At the time of transfection, log-phase cells were subcultured, and for each transfection 1 million cells were added to $2.5 \mu \mathrm{g}$ vector DNA as well as $100 \mu 1$ of the Amaxa Nucleofection solution. Cells were transfected using an optimized Amaxa Transfection program (T-30). After transfection, cells were transferred to a $1.5 \mathrm{ml}$ Eppendorf tube filled with RPMI medium for 15 minutes, and then to a 6-well plate filled with the recommended cell line medium. Twenty-four hours after transfection, the medium was renewed. In the case of stable transfections, selection was start- 
ed 48 hours after transfection using media with $0.8 \%$ or $1.2 \%$ puromycin (for SW480/SW837 and HT-29, respectively). This selection process was employed to ensure that only cells expressing the transfected vector remained. For the stable cell lines, single cell cloning (SCC, single cell clone) was performed after selection to ensure experimentation with homogenous cell populations. The process works as follows: a cell solution is serially diluted to about one cell per $300 \mu \mathrm{l}$ of medium. This solution is then pipetted into a 96-well plate. Twenty-four hours later, each well of the 96-well plate is carefully screened by microscopy, and each well containing only a single cell is marked. This cell will then start to divide, grow into a colony, and eventually fill up a whole cell culture flask, forming a population based on single cell, hence "single cell cloning".

\subsection{Cell lysis and western blot analysis}

After removal of the cell culture medium, around $100 \mu 1$ of a NP-40 based cell lysis buffer containing protease inhibitor (Proteo Block, Fermentas, St. Leon-Rot, Germany), DTT (AppliChem, Darmstadt, Germany) and PhosphoStop (Roche, Mannheim, Germany) was added to each well of a 6-well plate. Next, cells were scraped from the culture surface, and the suspension was transferred to Eppendorf tubes. Cells were then lysed on ice for 30 minutes. The cell suspension was cleared from cell debris by centrifugation at $4^{\circ} \mathrm{C}$, and the supernatant containing the protein was stored at $-20^{\circ} \mathrm{C}$. For separate extraction of nuclear and cytosolic protein fractions, cells were lysed using a NP-40-based lysis buffer, and fractions were separated by serial centrifugation. Prior to using the proteins for western blotting, a 4X SDS-based loading buffer was added and the amount needed for blotting was incubated at $95^{\circ} \mathrm{C}$ for 5 min. Blotting was performed using a semi-dry blotting apparatus (Biometra, Göttingen, Germany). For blocking, 5\% blocking milk was used. All antibodies were used according to their respective datasheets. Antibodies were used in at the respective conditions: anti-TCF7L2 (5\% BSA, 1:10,000, incubation at $4^{\circ} \mathrm{C}$ for $16 \mathrm{~h}$; Abcam, Cambridge, UK), anti- $\beta$-actin $(5 \%$ milk, $1: 1,000$, incubation at $4^{\circ} \mathrm{C}$ for $16 \mathrm{~h}$; Sigma-Aldrich, Steinheim, Germany), anti-active- $\beta$ - 
catenin ( $5 \%$ milk, 1:2,000, incubation at $4{ }^{\circ} \mathrm{C}$ for $16 \mathrm{~h}$; Millipore, Schwalbach, Germany) and anti- $\beta$-catenin $\left(5 \%\right.$ milk, $1: 2,000$, incubation at $4{ }^{\circ} \mathrm{C}$ for $16 \mathrm{~h}$; Santa Cruz Biotechnology, Heidelberg, Germany).

\subsection{Irradiation experiments}

For irradiation experiments, log-phase cells were seeded into 6-well plates at specific cellline-dependent cell densities, depending on cellular growth characteristics (between 250 and 1,000 cells per well were seeded). Subsequently, sixteen hours after seeding, cells were irradiated with a single dose of 1, 2, 4, 6 and 8 Gy of X-rays at 1 Gy/min (Gulmay Medical Ltd, Camberley, UK). Each experiment contained an unirradiated control set, which was exactly treated like the irradiated set. Depending on cellular growth characteristics, clones were grown for 8 days (HT-29), 10 days (SW480) or 21 days (SW837). Optimal cell densities, growth time and other growth condition were determined in test experiments. During the growth period, the culture medium was refreshed every third day. At the end of the growth period, cells were taken out of the incubator, medium was removed, and the colonies were fixed with $70 \%$ ethanol and stained using either crystal-violet (SW480) or haemalaun (SW837 and HT-29). Colonies with more than 50 cells were scored as survivors (Franken et al. 2006). Each experiment was performed in triplicate and independently repeated three times.

\subsection{Cell cycle}

Cell cycle distribution was analyzed before, and 4 and 8 hours after irradiation at 4 Gy. Cell cycle analyses were performed as follows: Cells were harvested by trypsinization at the indicated time points. Cell membranes were permeabilized at $-20^{\circ} \mathrm{C}$ overnight using $70 \%$ methanol. Subsequently, cells were treated with $10 \mu \mathrm{l} / \mathrm{ml}$ RNase A (Qiagen) for $30 \mathrm{~min}$ at $37^{\circ} \mathrm{C}$, and stained with $20 \mu \mathrm{l} / \mathrm{ml}$ propidium iodide (Sigma-Aldrich) for $20 \mathrm{~min}$ at $37^{\circ} \mathrm{C}$. DNA content was measured by flow cytometry (FACScan; BD Bioscience, Germany), and at least 30,000 cells were counted for each sample. All experiments were independently repeated three times. Results were analyzed using the FlowJo software package (Tree Star, Ashland, OR). 


\subsection{DNA damage repair}

DNA damage repair was studied by evaluating the cell's ability to sufficiently repair DNA double strand breaks (DSBs). Towards this goal, the levels and kinetics of the phosphorylated form of the histone protein $\mathrm{H} 2 \mathrm{AX}$, which accumulates at sites of DSBs (Lobrich et al. 2010), were studied. Cells were grown on microscopy slides for 16 hours, irradiated at 2 Gy and fixated with $2 \%$ formaldehyde/phosphate-buffered saline for $15 \mathrm{~min}$. Following fixation, cells were permeabilized with $0.2 \%$ Triton $\mathrm{X}-100$ /phosphate-buffered saline/ $1 \%$ fetal bovine serum (Pan, Aidenbach, Germany) for $10 \mathrm{~min}$ on ice, and blocked with 5\% bovine serum albu$\min / 1 \%$ fetal bovine serum/phosphate-buffered saline. Slides were incubated over night at $4^{\circ} \mathrm{C}$ with a mouse anti- $\gamma \mathrm{H} 2 \mathrm{AX}$ antibody (Millipore) and an appropriate secondary antibody (fluorescence-coupled mouse anti-rabbit antibody) (Millipore). Nuclei were counterstained with 4',6-diamidino-2-phenylindole (Sigma-Aldrich) and mounted using VECTASHIELD (Vector Laboratories, Peterborough, UK). Radiation-induced $\gamma \mathrm{H} 2 \mathrm{AX}$ foci were counted in at least 100 cells per sample using a fluorescence microscope (DM6000; Leica, Wetzlar, Germany). Pictures were taken using the Leica Application Suite.

\subsection{TCF transcriptional activity}

A TCF reporter assay (TOPFLASH/FOPFLASH assay, Korinek et al. 1997) containing two luciferase reporter plasmids was used to measure the TCF transcriptional activity. The first plasmid (TOPFLASH, Millipore) contains six TCF binding sites, attached to a firefly luciferase which is activated upon binding of TCFs. The second plasmid (FOPFLASH) contains six mutated TCF binding sites and serves as a negative control. A second vector (CMV-renilla), constitutively expressing a renilla luciferase, is used for normalization for differences in transfection efficiency and cellular viability. This system measures the transcriptional baseline activity of the TCFs. Furthermore, the inducibility of transcriptional activity was tested by cotransfection of mutated (S33Y, activating mutation) $\beta$-catenin. $\beta$-catenin in its active state binds to TCF7L2 and increases the transcriptional activity of the complex, thus enhancing 
reporter activity (Schwarz et al. 2003). The assay was performed as follows: cells were cotransfected with either 100ng TOP plasmid or 100ng FOP plasmid and 10ng of the CMVrenilla plasmid. To test the inducibility of the reporter assay, 50ng S33Y- $\beta$-catenin plasmid was co-transfected as well. In all experiments cells were grown for 24 hours after transfection and then lysed using a proprietary lysis buffer (Promega, Mannheim, Germany). Lysates were transferred to a 96-well plate, luciferase substrate was added and the luciferase activity was measured using a plate reader (Mithras LB940, Berthold Technologies GmbH, Bad Wildbad, Germany). After background-subtraction and normalization, relative light units (RLU) were divided (TOP divided by FOP) to obtain a signaling activity factors. Each experiment was performed in triplicate and independently repeated three times.

\subsection{RNA isolations and PCR}

RNA was isolated using the Qiagen RNA Extraction kit according to the manufacturer's manual. All samples were treated with DNase. To ensure sample purity, only RNA samples with 260/280 values around 1.8 were used. PCR reactions were performed in $25 \mu$ format; each reaction contained cDNA reverse-transcripted from 500ng RNA, SYBR ${ }^{\circledR}$ Green PCR Master Mix (Applied Biosystems), dNTPs. DTT and primer mix. The following optimized PCR protocol was used: pre-cycling-degradation for $10 \mathrm{~min}$ at $95^{\circ} \mathrm{C}$, annealing for $0.5 \mathrm{~min}$ at $60^{\circ} \mathrm{C}$, elongation for $1 \mathrm{~min}$ at $72^{\circ} \mathrm{C}$, degradation for $30 \mathrm{sec}$ at $95^{\circ} \mathrm{C}, 40$ cycles were run. For each PCR experiment, a melting curve measurement was performed to ensure productspecificity. Primers were designed as exon-spanning and optimized before usage to achieve high efficiency and specificity. The resulting cycle threshold $(\mathrm{Ct})$ values were normalized to the mean of three housekeeping genes (i.e. HPRT1, YWHAZ and GAPDH). The $-\Delta \Delta C T$ algorithm was applied to analyze the relative changes in gene expression between two cell populations (Livak and Schmittgen 2001). 


\subsection{Statistical analysis}

For the statistical analysis of irradiation and cell cycle experiments, a multiple linear regression model was used. In case of the irradiation experiments, the normalized surviving fraction was described as the dependent variable, given the independent variables of irradiation dose, group (negative control versus SCC) and replicate pairing (experiments that were performed at the same time). In case of the cell cycle analysis, a similar multiple linear regression was used to model the percentage of cells in G2/M phase as the dependent variable, given the independent variables of time-after-radiation, group (negative control versus SCC) and replicate pairing. An analysis of variance was performed on these models to identify significant variables and interaction effects. For all other analyses, an unpaired two-tailed Student's t-test was used.

For all analyses P-values, $<0.05$ was considered significant, and P-values $<0.001$ were considered highly significant. Data are represented as mean \pm standard error of the mean. All analyses were performed using the free statistical software R (version 2.9.2).

\section{SUMMARY OF RESULTS}

\subsection{TCF7L2 expression is correlated to radioresistance}

In previous studies, our group demonstrated that the transcription factor TCF7L2 was linked to resistance to radiation therapy. In 2005 Ghadimi et al. profiled primary rectal cancers that were either resistant or sensitive to preoperative chemoradiotherapy, and identified differentially expressed genes. TCF7L2 was one of the genes that were over-expressed in resistant tumors, and, in fact, TCF7L2 was one of the most promising targets based on a series of statistical criteria. The goal of my doctoral thesis was to elucidate the functional relevance of the observed overexpression of TCF7L2 in mediating resistance to radiation therapy.

First, we aimed to recapitulate the respective in-vivo findings made by Ghadimi et al. in an invitro system using established colorectal cancer cells lines. Towards this goal, western blot 
analyses of eight colorectal cancer cell lines were performed and expression levels of TCF7L2 were determined (Figure 1A). Next, the expression levels were correlated to the respective radiation sensitivities of these cell lines (surviving fraction at 2 Gy of X-Rays, as previously reported by Spitzner et al. in 2010). TCF7L2 protein levels were positively correlated to resistance to radiation therapy (Figure 1B; i.e. cells with high TCF7L2 levels are relatively resistant, while cells with low levels are relatively sensitive).

A)

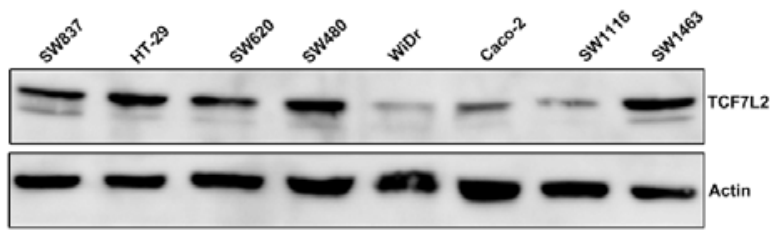

B)

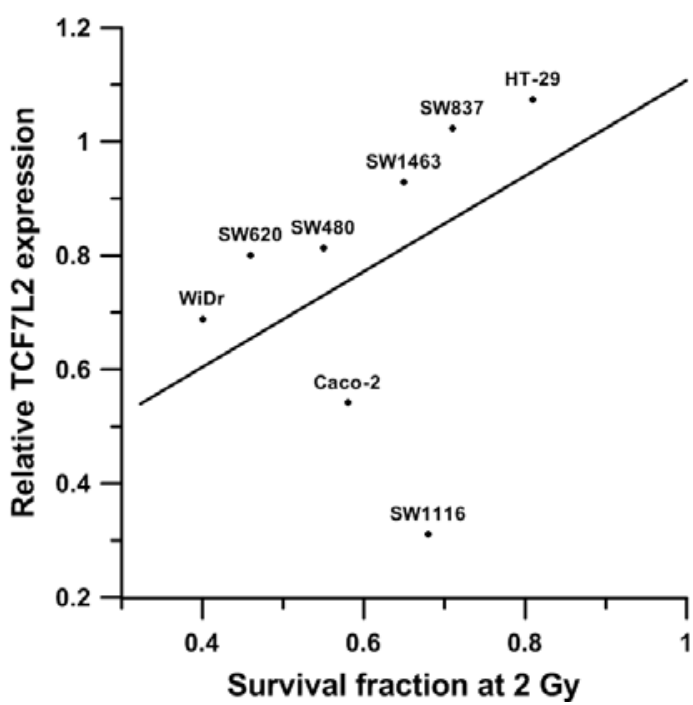

Figure 1 A) Representative western blot analysis of TCF7L2 expression levels in eight colorectal cancer cell lines B) Correlation between TCF7L2 expression levels and resistance to radiation measured as survival fraction at 2 Gy of X-rays.

These results prompted a more detailed analysis of the relationship of TCF7L2 expression and radioresistance. To study whether TCF7L2 is in fact involved in mediating radioresistance, loss-of-function experiments using RNA-interference were performed. RNA-interference is a molecular mechanism, which uses short RNA molecules to trigger cells to degrade a specific mRNA in a sequence-specific manner, ensuring high specificity. For more details and an indepth explanation, please refer to the very good review by Rana 2007.

\subsection{Inhibition of TCF7L2 is associated with increased radiosensitivity}

Based on these results, three colorectal cancer cells lines were selected to perform loss-offunction experiments. Cell lines with both high expression levels of TCF7L2 and high re- 
sistance to radiation were considered to be most suitable. SW837, SW480 and HT-29 best met these criteria. Using the Amaxa Nucleofection transfection system, each cell lines was transfected with two different shRNA constructs (referred to as shRNA_1 and shRNA_2 from here on). Each vector expresses a shRNA targeting TCF7L2. shRNA (short-hairpin RNA) molecules are constitutively expressed by the host cell and stably silence their target gene using the RNA-interference mechanism briefly described above. As a negative control (shNeg), a vector expressing a "scrambled" shRNA sequence, whose target sequence does not exist in the host cell's DNA, was used. This control is needed to account for cellular changes due to transfection, selection and expression of an artificial RNA sequence. To obtain homogeneous cell populations, cells were selected using puromycin-containing medium until only cells expressing the shRNA vector remained. At this point, single cell cloning was performed. Once homogeneous single cell clone populations (SCC) were established, the actual irradiation experiments were performed. Initially, for SW837, five homogeneous SCC populations were established from the heterogeneous shRNA_1 population and nine from shRNA_2; for SW480, ten from shRNA_1, eleven from shRNA_2; and for HT-29, eleven from shRNA_1, and ten from shRNA_2.

Prior to the irradiation experiments, those SCC populations that showed the most prominent downregulation of TCF7L2 were selected for further experimentation. Two populations for each vector were chosen, in total 12 cell populations (four per cell line) were used. All populations showed pronounced reduction of TCF7L2 protein levels compared to the nonsilencing control (Figure 2).

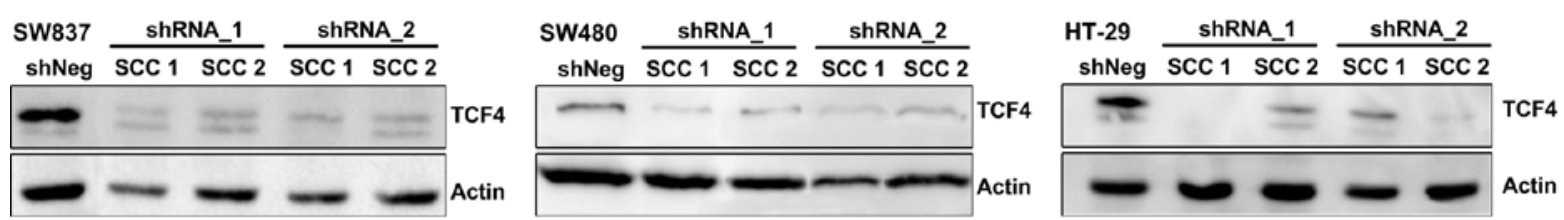

Figure 2: Expression levels of TCF7L2 after RNAi-mediated inhibition using two different shRNA vectors in three colorectal cancer cell lines. shNeg served as control. 
Irradiation experiments were performed using irradiation doses of 1, 2, 4, 6 and 8 Gy. Depending on cellular growth characteristics, clones were grown for 8 days (HT-29), 10 days (SW480) or 21 days (SW837).

At the indicated time points, colonies with more than 50 cells were counted as "survivor", i.e. cells/colonies which were able to survive the damage induced by irradiation. This procedure is standard procedure in radiation oncology, and the number 50 is chosen due to the fact that even a cell that was severely damaged by radiation might still be able to divide up to 5 times before dying. On the other hand it is very unlikely that a severely damaged cell will divide as often as it is needed to form a colony of 50 or more cells (Puck and Marcus 1956). The results of the irradiation experiments are shown in figure 3 (representative irradiation curves).

Compared to the non-silencing control, cells expressing the shTCF7L2 were more severely affected by irradiation, i.e. fewer cells survived. A highly significant radiosensitization was observed in all SW837 and SW480 SCCs $\left(\mathrm{P}<10^{-16}\right.$ and $\mathrm{P}<10^{-16}$, respectively; multiple linear regression model), while HT-29 SCCs $(\mathrm{P}=0.7$, multiple linear regression) were not affected at all. Since there is no prominent difference in e.g. the mutational setup of these three cell lines or any other apparent reason, this clear divergence between SW480 and SW837 on the one hand, and HT-29 on the other hand, remained to be explained at this point.
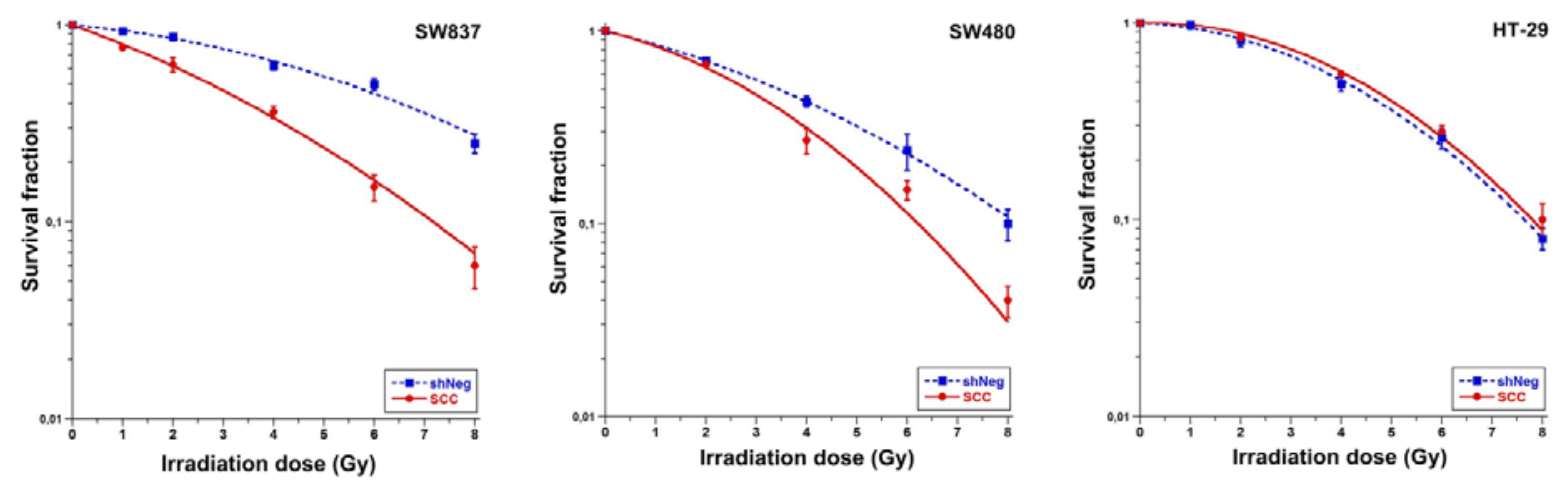

Figure 3 Survival curves for three colorectal cancer cell lines. Curves show survival after 0, 1, 2, 4, 6 and 8 Gy of X-rays in one representative shTCF7L2 clone for each cell line and shNeg. 
The irradiation experiment clearly showed that the inhibition of TCF7L2 causes a distinct radiosensitization in at least a subset of colorectal cancer cell lines.
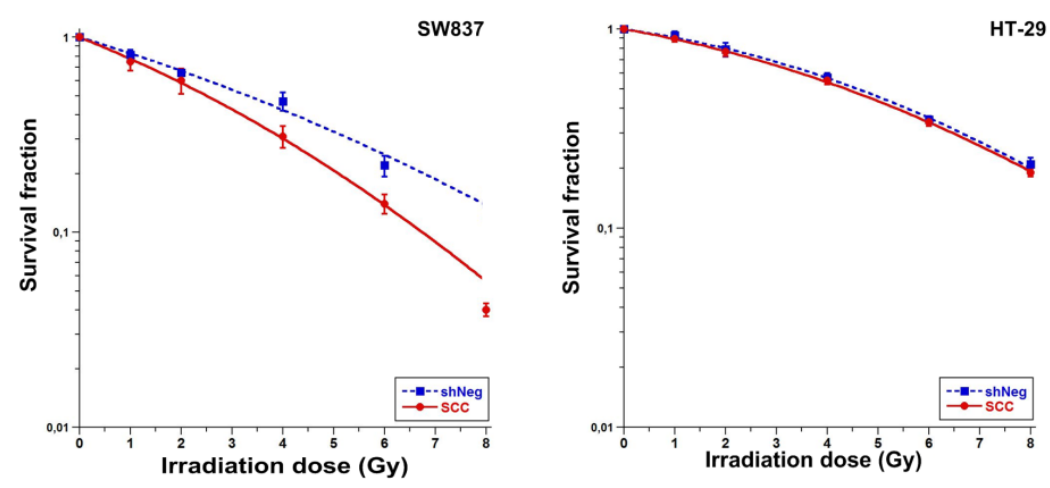

Figure 4 Survival curves for two colorectal cancer cell lines. Curves show survival after combined 5-FU based chemoradiotherapy and irradiation at 1,2, 4, 6 and 8 Gy of X-rays in a representative shTCF7L2 clone and shNeg.

As stated above, the standard therapy for locally advanced rectal cancers consists of 5-FUbased chemoradiotheray. Due to this fact, a treatment regimen combining $3 \mu \mathrm{M}$ of $5-\mathrm{FU}$ followed by irradiation was used as well. This setting was tested in SW837 and HT-29. Compared to the radiation-only experiments, very similar results were obtained. Again, HT-29 wasn't affected by the inhibition of TCF7L2. Representative curves are shown in figure 4 . Next, to further understand the reason for the observed radiosensitization and to elucidate the difference between the cell lines (i.e., no effect in HT-29), functional downstream experiments were performed.

\subsection{Impaired cell cycle control and reduced DNA damage repair increase sensitivity}

Subsequent experiments were performed in SW837, representative of a cell line affected by TCF7L2 inhibition, and HT-29, representative of a cell line unaffected by TCF7L2 inhibition. Cell cycle distribution at the time of irradiation, cell cycle control after irradiation, and an adequate response to DNA damage are important factors determining cellular survival after radiation (O'Driscoll and Jeggo 2006). To test whether the observed sensitization is due to an 
impairment of one or more of these processes, cell cycle and DNA damage response experiments were performed in SW837 and HT-29 SCC populations.

A

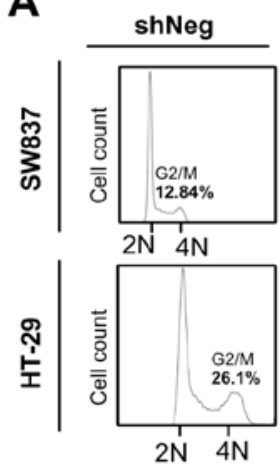

C

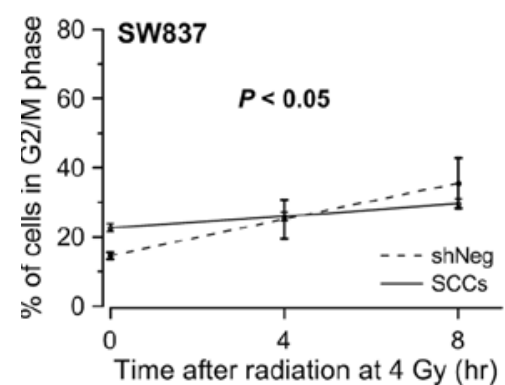

B

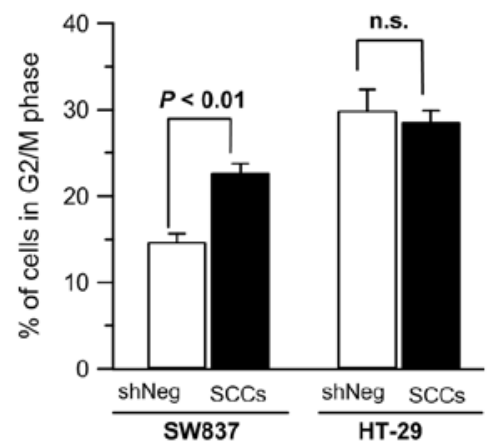

D

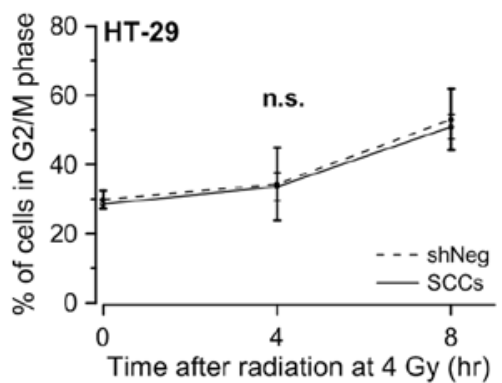

Figure $5 \mathrm{~A}+\mathrm{B}$ ) Cell cycle distribution at the time of irradiation in one representative shRNA clone and shNeg control in SW837 and HT-29. C + D) Cell cycle distribution 0, 4, and 8 hours after irradiation in one representative shRNA clone and shNeg control in SW837 and HT-29.

First, cell cycle distribution at the time of irradiation was studied using flow cytometry (exemplified in Figure 5A). Cells were seeded in parallel to the irradiation experiments to be able to directly correlate these results to the irradiation experiments. Compared to the nonsilencing control, an increase in G2/M phase cells was observed in SW837 SCCs (Figure 5B). Compared to other cell cycle phases, cells in G2/M phase are more sensitive to irradiation due to their higher DNA content (Seiwert et al. 2007), providing an explanation for the observed sensitization in the SW837 SCCs. In striking contrast to the SW837 SCCs, and fitting with previous results, no change in cell cycle distribution was observed in the HT-29 SCCs.

Next, the cell's ability to properly control cell cycle progression after irradiation was studied. Physiologically, eukaryotic cells arrest in G2/M phase after radiation damage to allow time 
for repair of DNA damage, and, importantly, not to progress through mitosis with a persistent damage (O'Driscoll and Jeggo 2006). To evaluate whether this control mechanism is affected by the inhibition of TCF7L2, cells were seeded and irradiated in parallel to the irradiation experiments, and cell cycle distribution was analyzed at 0,4 and 8 hours after irradiation. Indeed, an effect on the cell cycle control was observed in the SW837 SCCs compared to the non-silencing control (shNeg). In fact, the SW837 SCCs failed to adequately stop cell cycle progression after irradiation (Figure 5C), shown as an inadequately increased fraction of cells in the G2/M phase after irradiation. HT-29 SCCs did not differ from the non-silencing control (Figure 5D). SW837 SCCs continued cycling almost unaffected, providing further evidence that important resistance and survival mechanisms are impaired by the inhibition of TCF7L2 in SW837 SCCs. These result fit nicely with the observation that only the SW837 SCCs were sensitized to radiation therapy after inhibition of TCF7L2.

Next, experiments were performed to study the DNA damage repair response machinery. Sufficient repair of radiation-induced DNA damage, most importantly DNA double strand breaks (DSBs), is extremely important for the cell's ability to survive radiation (Bonner et al. 2008, Lobrich et al. 2010). To study the repair of DSBs, the presence and persistence of $\gamma \mathrm{H} 2 \mathrm{AX}$ foci was monitored. Phosphorylated H2AX proteins accumulate at the site of DNA double strand breaks as a part of the signaling cascade leading to the repair of the respective DNA damage (Lobrich et al. 2010). For each sample, three measurements were performed: without irradiation (negative control), 15 minutes after irradiation with 2 Gy, and 24 hours after irradiation. $\gamma \mathrm{H} 2 \mathrm{AX}$ foci were studied 15 minutes after irradiation to ensure that irradiation induced equal numbers of foci in all samples (representative microscopy pictures shown in figure 6A and C). This is of high importance since the repair rather than the induction of $\gamma \mathrm{H} 2 \mathrm{AX}$ foci is corre- 
lated with sensitivity to irradiation (Lobrich et al. 2010).
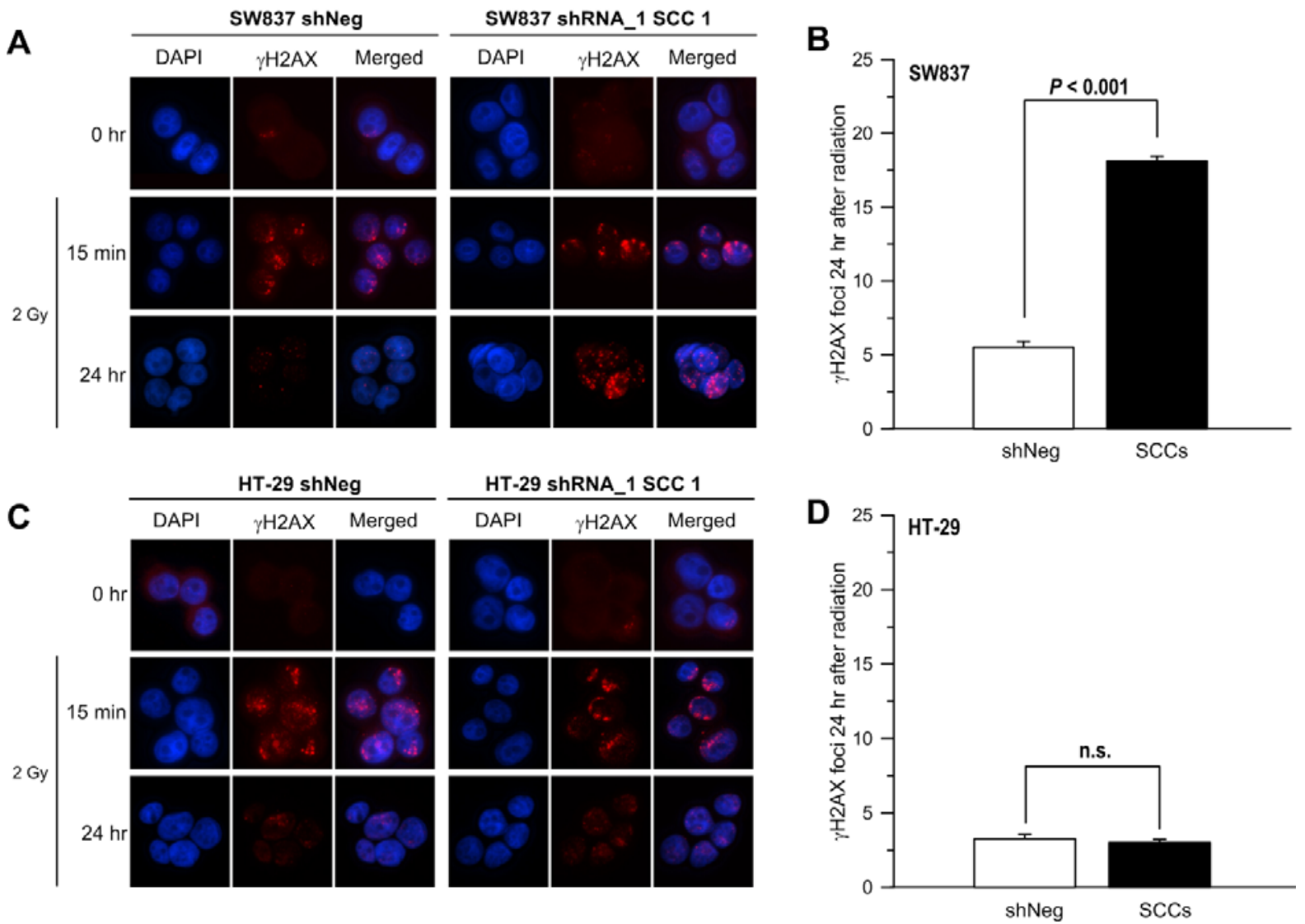

Figure $6 \mathrm{~A}+\mathrm{C}) \gamma \mathrm{H} 2 \mathrm{AX}$ foci measured 0,15 minutes, and 24 hours after irradiation with $2 \mathrm{~Gy}$ of $\mathrm{X}$-rays in one representative shRNA clone and shNeg in two cell lines. C + D) Comparison of remaining foci 24 hours after irradiation.

It is generally accepted that the persistence of foci 24 hours after irradiation correlates tightly with the cell's ability to sufficiently repair DNA double strand breaks, and, in turn, with resistance to irradiation (Dikomey et al. 1998). In all cell lines and clones induction of $\gamma \mathrm{H} 2 \mathrm{AX}$ foci was highly similar (induction time point $15 \mathrm{~min}$, figure $6 \mathrm{~A}+\mathrm{C}$ ) and statistically not significant. The SW837 non-silencing control was able to sufficiently repair damage and almost no foci persisted 24 hours after irradiation. In stark contrast, in the SW837 SCCs, most foci were still present at this time point, indicating persistent double strand breaks and impaired DNA damage repair. As a consequence, this results in an increased sensitivity to radiation, i.e., a reduced resistance (Figure 6B). The difference in DNA damage repair provides further insights into the cause of radiosensitization observed upon silencing of TCF7L2. HT-29 SCCs 
did not differ from the respective non-silencing control, and all populations repaired DSBs equally well (Figure 6D).

Taken together, these results fit together nicely (i.e., SW837 is functionally affected by the inhibition of TCF7L2 in all experiments, while HT-29 is not) and form a coherent picture. However, the exact underlying mechanism for this difference remains to be elucidated.

\subsection{Inhibition only affects active cell lines}

As explained above, TCF7L2 requires, in general (as part of canonical Wnt/ $\beta$-catenin signaling), activated $\beta$-catenin to be transcriptional active, and in fact the expression levels of TCF7L2 alone do not necessarily predict the level of transcriptional activity (Moon et al. 2004). The following hypothesis was put forward: not the expression level of TCF7L2 (as described above, all cell lines express very similar levels), but rather the transcriptional activity is responsible for the observed differences between SW837 and HT-29. To test this hypothesis, a TCF reporter assay was used to measure baseline levels and inducibility of TCF transcriptional activity.
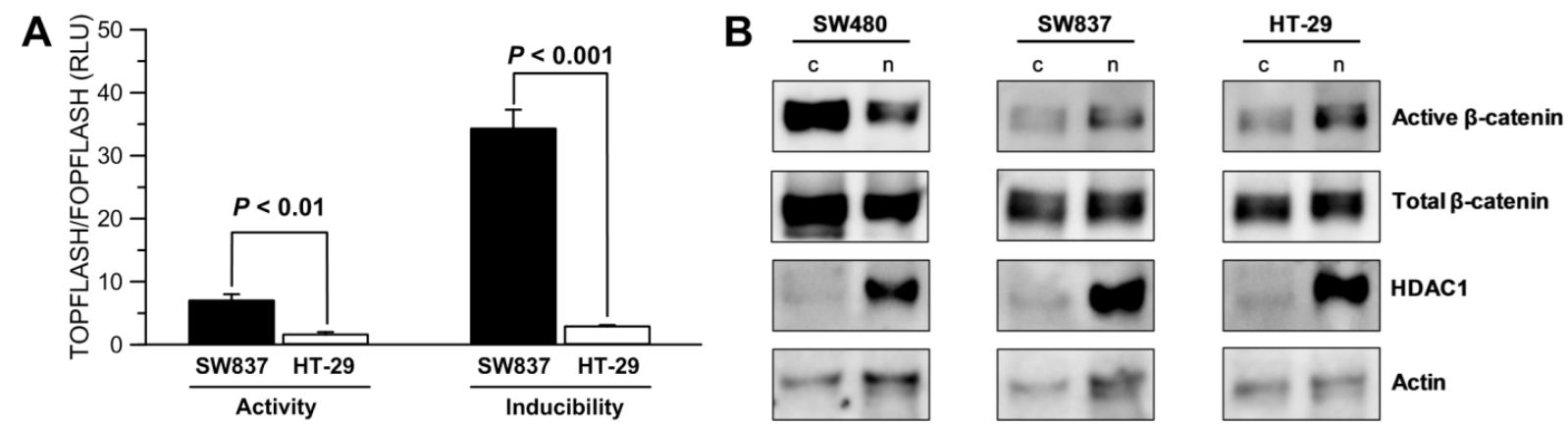

Figure 7 A) Baseline and induced TCF7L2 reporter activity measured using the TOPFLAHS/FOPFLASH reporter assay B) Comparison of cytosolic and nuclear active $\beta$-catenin in three colorectal cancer cell lines.

As expected, SW837 wild type cells showed prominent baseline reporter activity and pronounced inducibility (4.9-fold over baseline activity), indicative of high transcriptional activity. HT-29 wild type cells on the other hand showed only minor reporter activity, and only a slight increase in activity was observed after co-transfection of mutated $\beta$-catenin (Figure 
7A). To understand this difference in more detail, nuclear (representing the transcriptionally active form) and cytosolic (inactive) protein levels of $\beta$-catenin were compared separately in SW837 and HT-29 wild type cells by western blotting ( $\beta$-catenin levels were studied in more details since, as described above, TCF7L2 expression levels were comparable in SW837 and HT-29). Similar nuclear and cytosolic levels were observed in both cell lines, suggesting that the observed effects are independent of $\beta$-catenin and rely on the transcriptional activity of TCF7L2 (Figure 7B).

\section{5 shTCF7L2 deregulates Wnt/TCF7L2 signaling}

As explained above, TCF7L2 is the main transcription factor of canonical Wnt signaling, and regulates the transcription of a plethora of downstream genes (Ravindranath et al. 2008). To demonstrate that silencing of TCF7L2 results in a transcriptional deregulation of Wnt/TCF7L2 signaling in SW837, but not in HT-29, the expression levels of select TCF7L2 target genes were measured (He et al. 1998, Niida et al. 2004, Tetsu and McCormick 1999). Using real-time PCR, a considerable deregulation of several important target genes was observed: CCND1, DKK1 and MYC were deregulated in SW837, with average fold-changes of 2.4 (CCND1, up-regulated following silencing of TCF7L2), 18.4 (DKK1, down-regulated) and 2.7 (MYC, down-regulated). Notably, in HT-29, these downstream target genes either showed no prominent deregulation (CCND1) or their deregulation was inconsistent (DKK and MYC). The respective levels of deregulation are shown in figure 8 .

Collectively, these results demonstrate that RNAi against TCF7L2 resulted in a transcriptional deregulation of Wnt/TCF7L2 signaling in SW837, which was associated with a significant sensitization to clinically relevant doses of X-rays. Again, HT-29 was not affected by the inhibition of TCF7L2. Further work is warranted to fully understand the relevance of the regulation of TCF7L2 target genes and the underlying mechanism causing the observed sensitization 

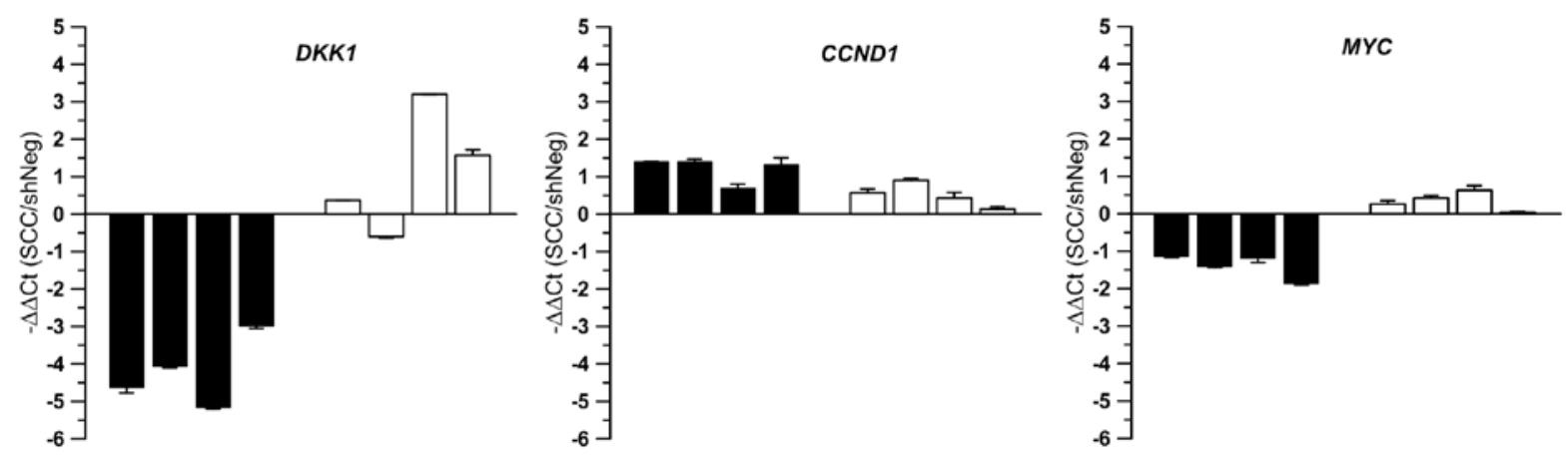

SW837 SCCs $\square$ HT-29 SCCs

Figure 8 Transcriptional deregulation of three Wnt/TCF7L2 target genes measured in four shRNA clones each in two colorectal cancer cell lines.

\section{SUMMARY AND CONCLUSION}

In this doctoral thesis, the effects of TCF7L2 mediating resistance to irradiation were studied. Previously, gene expression signatures of primary rectal cancers, classified as either resistant or sensitive to pre-operative (chemo-) radiotherapy, were compared, and TCF7L2 was found to be significantly overexpressed in the resistant tumors (Ghadimi et al. 2005). Consequently, TCF7L2 was considered a promising target gene to sensitize a priori resistant tumors. Here, the functional relevance of TCF7L2 for mediating radioresistance in an in-vitro setting was elucidated. TCF7L2 protein expression was positively correlated with resistance to irradiation and its RNA-mediated silencing led to a significant (chemo-)radiosensitization in SW837 and SW480 cells, whereas HT-29 cells were not sensitized at all. Sensitization in SW837 (TCF7L2-signaling active cell line) was a consequence of functional changes in cell cycle distribution, impaired cell cycle control, and impaired DNA damage response. HT-29 SCCs (TCF7L2-signaling inactive cell line) did not show any functional changes after inhibition of TCF7L2. All results coherently point to the fact that HT-29 cells apparently do not need TCF7L2 for mediating resistance to irradiation and are therefore not impacted by its inhibition. SW837 cells on the other hand need TCF7L2 and are severely affected by the inhibition of its transcription program, causing a pronounced sensitization. 
In conclusion, TCF7L2 was identified as functionally relevant for mediating resistance of colorectal cancer cells to (chemo-)radiotherapy with potential significance for future treatment options, e.g. targeting TCF7L2 prior to (chemo-)radiotherapy. Furthermore, these data suggest that only cell lines with active Wnt/TCF signaling are sensitized upon silencing of TCF7L2, providing a possible way to stratify tumors in the future, and to make treatment decisions based on the activity of this pathway. Finally, these results functionally link the Wnt signaling pathway to resistance to (chemo-)radiotherapy in colorectal cancer, which represents a novel finding. These results have been published in 2011 in Carcinogenesis.
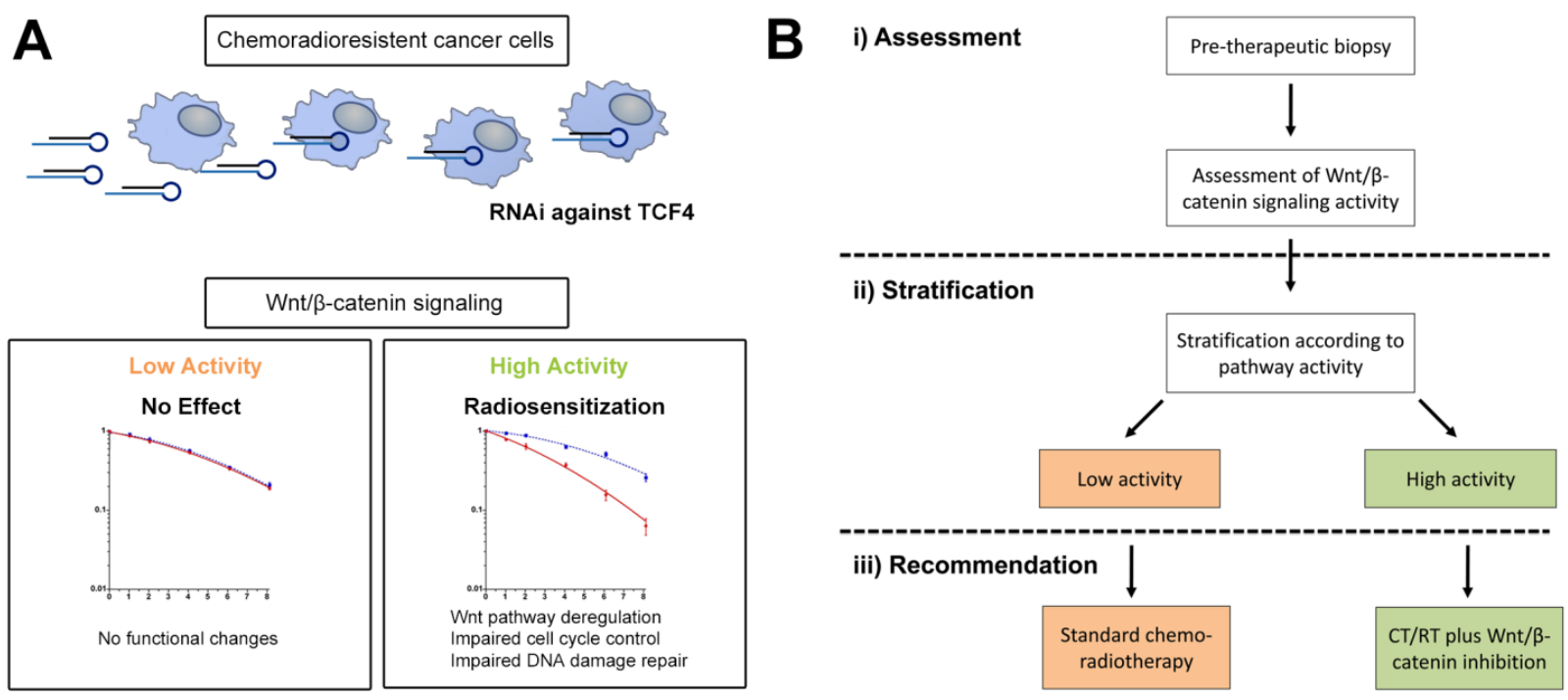

Figure 9 A) Mechanistic model for the novel role of Wnt/TCF7L2 signaling in sensitization after TFC7L2 silencing. B) Potential pre-operative treatment stratification based on Wnt/TCF7L2 activity.

Figure 9A summarizes the main results of this study and proposes a potential algorithm for stratification of primary rectal cancers based on the activity of the Wnt/ $\beta$-catenin/TCF7L2 signaling pathway (Figure 9B).

\section{OUTLOOK}

Since the Wnt/ $\beta$-catenin pathway and TCF7L2 signaling are extremely complex, several questions remain to be answered in future studies. While these experiments indicate that the ob- 
served sensitization is independent of $\beta$-catenin, the precise role of $\beta$-catenin in mediating resistance remains to be elucidated. RNA interference experiments targeting $\beta$-catenin and other members of the Wnt signaling cascade might help to understand in detail if TCF7L2 signaling is indeed the only factor required for chemoradiosensitization or if resistance is an result of a more complex interaction.

Furthermore, the exact mechanism of sensitization is not yet understood, i.e. which set of TCF7L2 downstream targets directly mediates the sensitization effect. Gene expression microarray analyses before and after silencing of TCF7L2 might provide valuable insights and a set of potentially relevant target genes to study in functional experiments.

Finally, experiments using xenograft models are warranted to replicate these observations in an in-vivo setting, and to take the first step towards implementing these results in a clinical setting.

$\beta$-catenin knockdown experiments and xenograft experiments in mice are currently being conducted. 


\section{REFERENCES}

1. Bonner WM, Redon CE, Dickey JS, Nakamura AJ, Sedelnikova OA, Solier S, and Pommier Y, (2008): GammaH2AX and cancer. Nat Rev Cancer, $\underline{8}(12)$ 957-67

2. Clevers H, (2006): Wnt/beta-catenin signaling in development and disease. Cell, 127(3) 469-80

3. Cunningham D, Atkin W, Lenz HJ, Lynch HT, Minsky B, Nordlinger B, and Starling N, (2010): Colorectal cancer. Lancet, 375(9719) 1030-47

4. Dikomey E, Dahm-Daphi J, Brammer I, Martensen R, and Kaina B, (1998): Correlation between cellular radiosensitivity and non-repaired double-strand breaks studied in nine mammalian cell lines. Int J Radiat Biol, 73(3) 269-78

5. Franken NA, Rodermond HM, Stap J, Haveman J, and van Bree C, (2006): Clonogenic assay of cells in vitro. Nat Protoc, 1(5) 2315-9

6. Ghadimi BM, Grade M, Difilippantonio MJ, Varma S, Simon R, Montagna C, Fuzesi L, Langer C, Becker H, Liersch T et al., (2005): Effectiveness of gene expression profiling for response prediction of rectal adenocarcinomas to preoperative chemoradiotherapy. $\mathrm{J}$ Clin Oncol, 23(9) 1826-38

7. He TC, Sparks AB, Rago C, Hermeking H, Zawel L, da Costa LT, Morin PJ, Vogelstein B, and Kinzler KW, (1998): Identification of c-MYC as a target of the APC pathway. Science, $\underline{281}(5382)$ 1509-12

8. Howlader N, Noone AM, Yu M, and Cronin KA, (2012): Use of Imputed Populationbased Cancer Registry Data as a Method of Accounting for Missing Information: Application to Estrogen Receptor Status for Breast Cancer. Am J Epidemiol, 176(4) 34756

9. Klaus A and Birchmeier W, (2008): Wnt signalling and its impact on development and cancer. Nat Rev Cancer, $\underline{8}$ (5) 387-98

10. Korinek V, Barker N, Morin PJ, van Wichen D, de Weger R, Kinzler KW, Vogelstein B, and Clevers H, (1997): Constitutive transcriptional activation by a beta-catenin-Tcf complex in APC-/- colon carcinoma. Science, 275(5307) 1784-7

11. Kuremsky JG, Tepper JE, and McLeod HL, (2009): Biomarkers for response to neoadjuvant chemoradiation for rectal cancer. Int J Radiat Oncol Biol Phys, 74(3) 67388

12. Livak KJ and Schmittgen TD, (2001): Analysis of relative gene expression data using real-time quantitative PCR and the 2(-Delta Delta C(T)) Method. Methods, 25(4) 402-8

13. Lobrich M, Shibata A, Beucher A, Fisher A, Ensminger M, Goodarzi AA, Barton O, and Jeggo PA, (2010): gammaH2AX foci analysis for monitoring DNA double-strand break repair: strengths, limitations and optimization. Cell Cycle, 9 (4) 662-9

14. Lynch HT and de la Chapelle A, (2003): Hereditary colorectal cancer. N Engl J Med, $\underline{348}(10)$ 919-32

15. Markowitz SD and Bertagnolli MM, (2009): Molecular origins of cancer: Molecular basis of colorectal cancer. N Engl J Med, 361(25) 2449-60

16. Moon RT, Kohn AD, De Ferrari GV, and Kaykas A, (2004): WNT and beta-catenin signalling: diseases and therapies. Nat Rev Genet, 5(9) 691-701

17. Niida A, Hiroko T, Kasai M, Furukawa Y, Nakamura Y, Suzuki Y, Sugano S, and Akiyama T, (2004): DKK1, a negative regulator of Wnt signaling, is a target of the betacatenin/TCF pathway. Oncogene, 23(52) 8520-6

18. Nusse R, (1999): WNT targets. Repression and activation. Trends Genet, 15(1) 1-3

19. O'Driscoll M and Jeggo PA, (2006): The role of double-strand break repair - insights from human genetics. Nat Rev Genet, Z1(1) 45-54 
20. Puck TT and Marcus PI, (1956): Action of $x$-rays on mammalian cells. J Exp Med, 103(5) 653-66

21. Rana TM, (2007): Illuminating the silence: understanding the structure and function of small RNAs. Nat Rev Mol Cell Biol, $\underline{8}$ (1) 23-36

22. Ravindranath A, O'Connell A, Johnston PG, and El-Tanani MK, (2008): The role of LEF/TCF factors in neoplastic transformation. Curr Mol Med, $\underline{8}(1) 38-50$

23. Sauer R, Becker H, Hohenberger W, Rodel C, Wittekind C, Fietkau R, Martus P, Tschmelitsch J, Hager E, Hess CF et al., (2004): Preoperative versus postoperative chemoradiotherapy for rectal cancer. N Engl J Med, 351(17) 1731-40

24. Schwarz M, Wanke I, Wulbrand U, Moennikes O, and Buchmann A, (2003): Role of connexin32 and beta-catenin in tumor promotion in mouse liver. Toxicol Pathol, $\underline{31}(1)$ 99-102

25. Seiwert TY, Salama JK, and Vokes EE, (2007): The concurrent chemoradiation paradigm--general principles. Nat Clin Pract Oncol, $\underline{4}(2)$ 86-100

26. Sobin LH and Fleming ID, (1997): TNM Classification of Malignant Tumors, fifth edition (1997). Union Internationale Contre le Cancer and the American Joint Committee on Cancer. Cancer, $\underline{80}(9)$ 1803-4

27. Tetsu O and McCormick F, (1999): Beta-catenin regulates expression of cyclin D1 in colon carcinoma cells. Nature, $\underline{398(6726)}$ 422-6 


\section{TITEL OF PUBLICATION}

Carcinogenesis. 2011 Dec;32(12):1824-31. Epub 2011 Oct 8.

\section{Silencing of the Wnt transcription factor TCF4 sensitizes colorec- tal cancer cells to (chemo-) radiotherapy.}

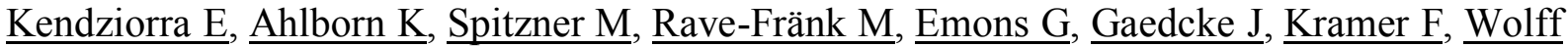

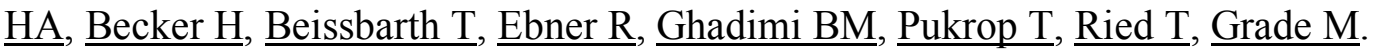

Department of General and Visceral Surgery, University Medical Center, Göttingen 37075, Germany. 


\section{ACKNOWLEDGEMENTS}

First and foremost, I would like to thank Prof. B. Michael Ghadimi for providing me with the opportunity to write my doctoral thesis in the Department of General, Visceral and Child Surgery, giving me the chance to present my work at conferences, and his strong support as my thesis supervisor. I'm extremely grateful to Dr. Marian Grade, without whom my work would not have been possible. I especially would like to thank him for providing me with this highly interesting and relevant research topic, invaluable guidance over the years and for being a great friend and mentor.

Moreover, I would like to thank Prof. H. Becker, the former chairman of the Department of General- and Visceral Surgery, for giving me the possibility to work in his department as a doctoral student.

Furthermore, I would like to thank Dr. Melanie Spitzner for her excellent support, and for providing me with experimental insights. Finally, I would like to thank all current and former lab members for being part of an enjoyable and fertile work environment. Especially, I would like to thank Kerstin Ahlborn and Georg Emons with whom I worked closely, as well as Birte Rösler, Jessica Eggert, and Antje Schneeberg.

I would also like to thank Margret Rave-Fränk, Tobias Pukrop, Jochen Gaedcke and Thomas Ried as well as Frank Kramer and Tim Beissbarth for fruitful discussions, their insights and invaluable experience. 


\section{CURRICULUM VITAE}

I was born on January 1st 1986 in Darmstadt. My parents are Michaela Kendziorra und Winfried Kendziorra, and I have two siblings, Fritz and Felice. I went to elementary school (EllyHeuss-Knapp-Schule) and Gynasium (Viktoriaschule) in Darmstadt, completed the Gynasium in 2005 and subsequently started the pre-clinical part of the medicine education in Hungary in an international program in English. After two years in Hungary, I passed the equivalent of the German "Physikum" and was accepted to continue my studies in the clinical part of the education at Georg August University in Göttingen. In 2009, I started to work on my doctoral thesis in the laboratory of Dr. Marian Grade and under the thesis supervision of Prof. B. Michael Ghadimi. My work focuses on the study of resistance mechanisms in colorectal cancer cell lines, and aims to identify novel treatment options for rectal cancers that are frequently resistant to pre-operative radiochemotherapy. In 2010, I was awarded a Gö4med stipend from the University Medical Center Göttingen for my thesis work. My thesis is titled "Silencing of the Wnt transcription factor TCF4 sensitizes colorectal cancer cells to (chemo-) radiotherapy." and was published in 2011 under the title "Silencing of the Wnt transcription factor TCF7L2 sensitizes colorectal cancer cells to (chemo-)radiotherapy" in the renowned peerreviewed journal Carcinogenesis. In February 2011, I started practical training as a final year student at the University Medical Center Göttingen, and subsequently completed medical school with the second state examination in July 2012. 


\section{Silencing of the Wnt transcription factor TCF4 sensitizes colorectal cancer cells to (chemo-) radiotherapy}

\author{
Emil Kendziorra, Kerstin Ahlborn, Melanie Spitzner, \\ Margret Rave-Fränk ${ }^{1}$, Georg Emons, Jochen Gaedcke, \\ Frank Kramer ${ }^{2}$, Hendrik A.Wolff ${ }^{1}$, Heinz Becker, \\ Tim Beissbarth ${ }^{2}$, Reinhard Ebner ${ }^{3}$, B.Michael Ghadimi, \\ Tobias Pukrop ${ }^{4}$, Thomas Ried ${ }^{3}$ and Marian Grade*
}

Department of General and Visceral Surgery, ${ }^{1}$ Department of Radiotherapy and Radiooncology and ${ }^{2}$ Department of Medical Statistics, University Medical Center, Göttingen 37075, Germany, ${ }^{3}$ Genetics Branch, National Cancer Institute, National Institutes of Health, Bethesda, MD 20892, USA and ${ }^{4}$ Department of Hematology/Oncology, University Medical Center, Göttingen 37075, Germany

*To whom correspondence should be addressed. Tel: +49 551 396944; Fax +49 5513912550

Email:mgrade@uni-goettingen.de

A considerable percentage of rectal cancers are resistant to standard preoperative chemoradiotherapy. Because patients with a priori-resistant tumors do not benefit from multimodal treatment, understanding and overcoming this resistance remains of utmost clinical importance. We recently reported overexpression of the Wnt transcription factor TCF4, also known as TCF7L2, in rectal cancers that were resistant to 5-fluorouracil-based chemoradiotherapy. Because Wnt signaling has not been associated with treatment response, we aimed to investigate whether TCF4 mediates chemoradioresistance. RNA interference-mediated silencing of TCF4 was employed in three colorectal cancer (CRC) cell lines, and sensitivity to (chemo-) radiotherapy was assessed using a standard colony formation assay. Silencing of TCF4 caused a significant sensitization of CRC cells to clinically relevant doses of $\mathrm{X}$-rays. This effect was restricted to tumor cells with high $\mathbf{T}$ cell factor (TCF) reporter activity, presumably in a $\beta$-catenin-independent manner. Radiosensitization was the consequence of (i) a transcriptional deregulation of Wnt/TCF4 target genes, (ii) a silencing-induced $G_{2} / M$ phase arrest, (iii) an impaired ability to adequately halt cell cycle progression after radiation and (iv) a compromised DNA double strand break repair as assessed by $\gamma \mathrm{H} 2 \mathrm{AX}$ staining. Taken together, our results indicate a novel mechanism through which the Wnt transcription factor TCF4 mediates chemoradioresistance. Moreover, they suggest that TCF4 is a promising molecular target to sensitize resistant tumor cells to (chemo-) radiotherapy.

\section{Introduction}

The standard treatment for locally advanced rectal cancers consists of preoperative 5-fluorouracil (5-FU)-based chemoradiotherapy followed by radical surgery (1). This multimodal approach reduces local recurrence (2). However, clinical response to chemoradiotherapy varies greatly, and a considerable percentage of rectal cancers are chemoradioresistant, even if intensified regimens are being pursued (3). This represents a substantial clinical and socioeconomic problem. Thus, it is of utmost clinical importance to determine the molecular characteristics underlying this resistance and to identify effective strategies to overcome it (4). Previously, we have therefore used gene expression profiling of resistant and responsive rectal cancers from patients who had been treated with preoperative chemoradiotherapy within a phase III clinical trial (2) and found TCF4 to be significantly overexpressed in resistant tumors (5).

Abbreviations: CRC, colorectal cancer; 5-FU, 5-fluorouracil; PCR, polymerase chain reaction; SCC, single-cell clone; TCF, T cell factor.
T cell factor 4 (TCF4), also known as TCF7L2, represents a key transcription factor that mediates canonical Wnt signaling, which plays a central role in embryonic development and in the maintenance of tissue homeostasis (6-8). Binding of Wnt ligands to cell surface receptors of the Frizzled family inhibits glycogen synthase kinase-3 $\beta$ mediated phosphorylation of the cotranscription factor $\beta$-catenin, leading to its stabilization and subsequent accumulation in the nucleus. This results in binding to members of the TCF and lymphoid enhancer-binding factor family of transcription factors (9), which in turn induces or represses transcription of a plethora of target genes (http://www.stanford.edu/group/nusselab/cgi-bin/wnt/).

Although aberrant Wnt signaling promotes colorectal cancer (CRC) development (6-8), it has not yet been associated with treatment resistance. In the present study, we therefore tested whether the observed overexpression of TCF4 is of functional relevance for mediating chemoradioresistance in rectal cancer.

\section{Materials and methods}

\section{Cell culture}

Human CRC cell lines Caco-2, HT-29, SW1116, SW1463, SW480, SW620, SW837 and WiDr were obtained from the American Type Culture Collection (ATCC, Manassas, VA) and cultured as described recently (10). Cell line identity has been confirmed by short tandem repeat profiling (10), and absence of Mycoplasma contamination was tested periodically by polymerase chain reaction $(\mathrm{PCR})$

\section{Establishment of stable single-cell clone populations}

Individual Expression Arrest ${ }^{\mathrm{TM}}$ lentiviral short-hairpin RNA constructs targeting TCF4, and a non-silencing control shRNA (shNeg), were obtained from Open Biosystems (Thermo Fisher Scientific, Huntsville, AL). The respective target sequences are listed in Supplementary Table S1, available at Carcinogenesis Online. As described recently (11), cells grown in log phase were transfected at $60-70 \%$ confluence with $2.5 \mu \mathrm{g}$ of linearized vector DNA using the Amaxa Nucleofector System (Lonza, Cologne, Germany), and stable singlecell clone (SCC) populations were subsequently established.

\section{Western blotting}

Cells were lysed in a lysis buffer containing 1\% NP-40 and protease and phosphatase inhibitor cocktail. To separate cytosolic and nuclear fraction, cells were lysed using two separate lysis buffers containing $0.5 \%$ and $1 \%$ NP- 40 , respectively, and a protease and phosphatase inhibitor cocktail. Blocking was performed using 5\% blotting grade milk. Membranes were probed overnight at $4^{\circ} \mathrm{C}$ with a rabbit anti-TCF4 antibody (1:10 000; Abcam, Cambridge, UK) or a mouse anti- $\beta$-catenin antibody (1:2000; Santa Cruz Biotechnology, Heidelberg, Germany) followed by a mouse anti-active- $\beta$-catenin antibody (1:2000; Millipore, Schwalbach, Germany). To confirm successful nuclear protein extraction, a rabbit anti-HDAC1 antibody was used (1:1000; New England Biolabs GmbH, Frankfurt am Main, Germany). Equal loading was ensured using a rabbit antiactin antibody (1:2000; Sigma-Aldrich, Steinheim, Germany). As secondary antibody, either a goat anti-rabbit or a rabbit anti-mouse peroxidase linked antibody (both 1:30 000; Acris Antibodies, Herford, Germany) was used. Membranes were developed using an enhanced chemiluminescence detection system (ECL Advanced, GE Healthcare, Buckinghamshire, UK) and signals were detected using a CCD-Camera (LAS-3000 Imager; Fuji-Film, Düsseldorf, Germany). The optical density was measured using the ImageJ software (NIH).

\section{Irradiation and determination of cell survival}

Tumor cells growing in log phase were seeded as single-cell suspensions into six-well plates and allowed to adhere overnight. Subsequently, cells were irradiated with a single dose of 1, 2, 4, 6 and 8 Gy of X-rays (Gulmay Medical Ltd, Camberley, UK), and a standard colony-forming assay was performed to determine the respective surviving fractions. After defined time periods (Supplementary Table S2 is available at Carcinogenesis Online), cells were fixed with $70 \%$ ethanol and stained. Colonies with $>50$ cells were scored as survivors. Non-irradiated cultures were used for data normalization. Experiments 
were performed as technical triplicates and independently repeated three times. To estimate the sensitivity to chemoradiotherapy, cells were exposed to $3 \mu \mathrm{M}$ of 5-FU (Sigma-Aldrich) for $16 \mathrm{~h}$ before irradiation, as described recently (10). Calculation of survival fractions (SF) was done using the equation $\mathrm{SF}-$ colonies counted/cells seeded $\times$ (plating efficiency/100). Survival variables $\alpha$ and $\beta$ were fitted according to the linear quadratic equation. Dose-modifying factors at $37 \%$ survival and survival variables $\alpha$ and $\beta$ have been calculated using KaleidaGraph (Synergy Software, Reading, PA) and are shown in Supplementary Table S3, available at Carcinogenesis Online.

\section{Cell cycle analysis}

Cell cycle distribution was analyzed before, and 4 and $8 \mathrm{~h}$ after irradiation at 4 Gy. Cell membranes were permeabilized at $-20^{\circ} \mathrm{C}$ overnight using $70 \%$ methanol. Subsequently, cells were treated with $10 \mu \mathrm{g} / \mathrm{ml}$ RNase A (Qiagen, Hilden, Germany) for $30 \mathrm{~min}$ at $37^{\circ} \mathrm{C}$ and stained with $20 \mu \mathrm{l} / \mathrm{ml}$ propidium iodide (Sigma-Aldrich) for $20 \mathrm{~min}$ at $37^{\circ} \mathrm{C}$. DNA content was measured by flow cytometry (FACScan; BD Bioscience, Heidelberg, Germany) and analyzed using the FlowJo software package (Tree Star, Ashland, OR).

Immunofluorescence and quantification of phosphorylated histone $\mathrm{H} 2 \mathrm{AX}$ foci formation

Cells were seeded onto microscope slides and allowed to adhere overnight. Sixteen hours later, slides were irradiated at 2 Gy and fixed with $2 \%$ formaldehyde/phosphate-buffered saline for $15 \mathrm{~min}$. Cells were permeabilized with $0.2 \%$ Triton X-100/phosphate-buffered saline/ $1 \%$ fetal bovine serum for 10 min on ice and blocked with $5 \%$ bovine serum albumin/1\% fetal bovine serum/ phosphate-buffered saline. Slides were incubated with a mouse anti-phosphohistone $\mathrm{H} 2 \mathrm{AX}$ antibody (1:1000; Millipore) over night at $4^{\circ} \mathrm{C}$, followed by incubation with a fluorescence-coupled mouse anti-rabbit secondary antibody (1:400; Alexa Fluor 594, Molecular Probes/Invitrogen, Darmstadt, Germany). Nuclei were counterstained with 4',6-diamidino-2-phenylindole (SigmaAldrich) and mounted using VECTASHIELD (Vector Laboratories, Peterborough, UK). Radiation-induced $\gamma \mathrm{H} 2 \mathrm{AX}$ foci were counted in at least 100 cells per sample using a fluorescence microscope (DM6000; Leica, Wetzlar, Germany) and the Leica Application Suite.

\section{TOP-FLASH/FOP-FLASH dual luciferase reporter assay}

Cells were transfected with $100 \mathrm{ng}$ TOP-FLASH plasmid containing six TCFbinding motifs (Millipore) or $100 \mathrm{ng}$ FOP-FLASH control plasmid containing six-mutated TCF-binding motifs (Millipore). Each sample was cotransfected with 10 ng renilla luciferase plasmid (pRL-CMV; Promega, Mannheim, Germany) to normalize for cell viability and transfection efficiency. To estimate the inducibility of TCF reporter activity, cells were transfected with $100 \mathrm{ng}$ of mutated $\beta$-catenin (S33Y; Millipore). This mutated protein cannot be inactivated by the degradation complex and translocates to the nucleus, where, after binding to TCFs, it leads to continuous reporter activity. Cell lysates were prepared using the Dual Luciferase Lysis Buffer (Promega), and luciferase activity was measured using a microplate reader (Mithras LB940; Berthold Technologies GmbH, Bad Wildbad, Germany). Promoter activity was calculated by dividing relative light units of specific TOP-FLASH and relative light units of non-specific FOP-FLASH.

\section{Real-time PCR}

Real-time PCR was performed as described recently (10), and the corresponding primer sequences can be found in Supplementary Table S4, available at Carcinogenesis Online. The resulting cycle threshold $(\mathrm{Ct})$ values were normalized according to the mean of three housekeeping genes (i.e. HPRT1, YWHAZ and $G A P D H$ ) and the $2^{-\triangle \Delta C \mathrm{~T}}$ algorithm (12) was applied to analyze the relative changes in gene expression between two cell populations.

\section{Statistical analysis}

A multiple linear regression model was used to describe the normalized surviving fraction as dependent variable, given the independent variables of irradiation dose, group (negative control versus SCC) and replicate pairing. A similar multiple linear regression was used to model the percentage of cells in $\mathrm{G}_{2} / \mathrm{M}$ phase as dependent variable, given the independent variables of timeafter-radiation, group (negative control versus SCC) and replicate pairing. An analysis of variance was performed on these models to reveal significant variables and interaction effects. For all other analyses, an unpaired two-tailed Student's $t$-test was used. $P$-values $<0.05$ were considered significant, and $P$ values $<0.001$ were considered highly significant. Data are expressed as mean \pm standard error of the mean. All analyses were performed using the free statistical software R (version 2.9.2).

\section{Results}

TCF4 expression correlates with chemoradioresistance in primary rectal cancers and in $C R C$ cell lines

Gene expression profiling of primary rectal cancers showed that the Wnt transcription factor TCF4 was significantly overexpressed in those tumors that were resistant to preoperative 5-FU-based chemoradiotherapy (5). To test whether we can recapitulate these findings in vitro, we first measured TCF4 protein expression levels in CRC cell lines (Supplementary Figure S1A is available at Carcinogenesis Online). We then compared these expression levels with the respective in vitro sensitivities of these cell lines to 5-FU-based chemoradiotherapy, which we recently reported (10) and could confirm that elevated TCF4 expression was positively correlated with resistance to in vitro chemoradiotherapy (Supplementary Figure S1B is available at Carcinogenesis Online).

\section{Silencing of TCF4 sensitizes CRC cell lines to irradiation}

To test whether the observed overexpression of TCF4 is functionally relevant for treatment resistance, RNAi-mediated silencing was employed in three p53-mutant CRC cell lines $(13,14)$ that expressed high levels of TCF4, i.e. SW837, HT-29 and SW480, using two short-hairpin RNA constructs. Stable SCC populations were established, and two SCCs from each vector were selected for further experimentation. Successful RNAi-mediated silencing of TCF4 was demonstrated using western blot analysis (Figure 1A).

Subsequently, selected SCC populations were irradiated at clinically relevant doses of X-rays, and the respective surviving fractions were measured using a standard colony-forming assay. Compared with the non-silencing control shRNA, silencing of TCF4 significantly increased sensitivity of all SW837 and SW480 SCCs to radiation $\left(P<10^{-16}\right.$ and $P<10^{-16}$, respectively; multiple linear regression model). In clear contrast, TCF4 silencing had no effect on HT-29 cells $(P=0.7$; Figure $1 \mathrm{~B}$, Supplementary Figure S2 is available at Carcinogenesis Online). Survival variables $\alpha$ and $\beta$ and dose modulation factors are shown in Supplementary Table S3, available at Carcinogenesis Online. Notably, in SW837 and SW480, TCF4 protein expression levels increased in response to treatment with 6 Gy of X-rays, whereas the expression of TCF4 was unchanged in HT-29 (Supplementary Figure S3 is available at Carcinogenesis Online).

Because the standard therapy for locally advanced rectal cancers comprises 5-FU-based chemoradiotherapy, we also employed a combination of $3 \mu \mathrm{M}$ of 5-FU and irradiation, as recently described (10) and observed very similar results. RNAi against TCF4 sensitized SW837 SCCs, but not HT-29 SCCs (Supplementary Figure S4 is available at Carcinogenesis Online).

\section{Silencing of TCF4 induces accumulation of SW837 cells in $G_{2} / M$} phase

Next, we investigated the cellular processes leading to the significant radiosensitization of SW837 SCCs. These and other follow-up experiments were performed exclusively in SW837 and HT-29. These two lines were chosen because both are highly chemoradioresistant, and we wanted to analyze the phenotype of resistance and sensitization, respectively.

Cells are not equally sensitive to radiation throughout the cell cycle but show increased radiation sensitivity in $\mathrm{G}_{2} / \mathrm{M}(15)$. We therefore performed cell cycle analyses of unirradiated SW837 and HT-29 SCC populations (exemplified in Figure 2A). Regarding SW837, an average of $23 \%$ of cells from different SCCs were captured in the $\mathrm{G}_{2} / \mathrm{M}$ phase compared with only $15 \%$ of cells from the non-silencing control (Figure 2B). This difference was statistically significant $(P<0.01)$ and suggests that radiosensitization of SW837 SCCs is at least in part attributable to an accumulation of cells in radiosensitive phases of the cell cycle (15). In clear contrast, no significant changes in cell cycle distribution were detected between HT-29 SCCs and the respective non-silencing control (Figure 2A and B). 

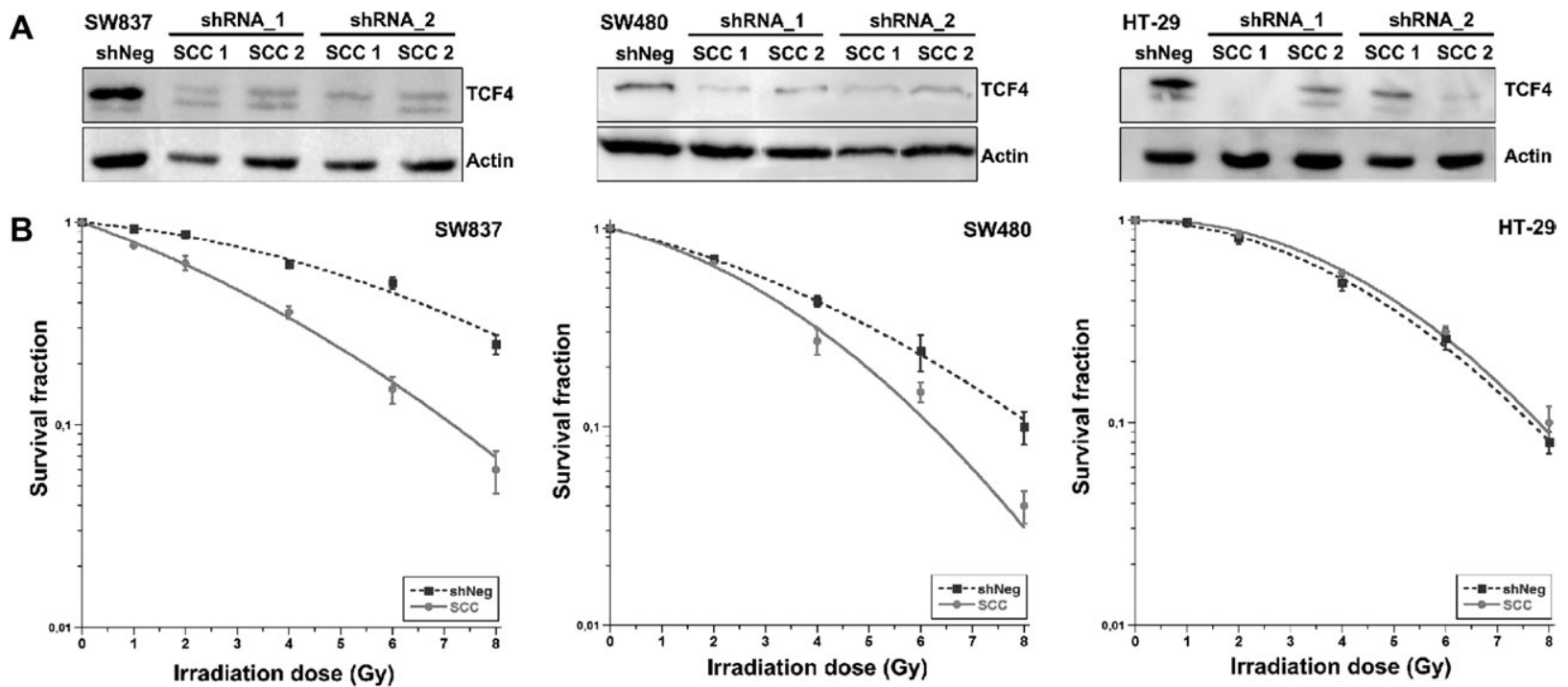

Fig. 1. Silencing of TCF4 sensitizes SW837 and SW480 to radiation. (A) Cell lines were transfected with two individual shRNA constructs targeting TCF4 and stable SCC populations were established. Compared with a non-silencing control shRNA (shNeg), all clones exhibited markedly reduced protein levels of TCF4. (B) Selected SCCs were irradiated at clinically relevant doses of X-rays. A standard colony-forming assay demonstrated that silencing of TCF4 significantly increased the radiosensitivity of SW480 and SW837 but not of HT-29 (exemplified for one representative SCC per cell line; see also Supplementary Figure S2, available at Carcinogenesis Online). Data are presented as mean of three independent experiments \pm standard error of the mean.

Silencing of TCF4 impairs radiation-induced $G_{2} / M$ arrest in SW837 Radiation exposure of eukaryotic cells results in a cell cycle delay required for DNA damage repair or induction of apoptosis (16). We therefore tested whether silencing of TCF4 leads to impaired cell cycle control after radiation as reflected by a lack of accumulation in $\mathrm{G}_{2} / \mathrm{M}$ phase. In the SW837 non-silencing control, the fraction of cells in $\mathrm{G}_{2} / \mathrm{M}$ phase markedly increased from $15 \%$ at the time of radiation to $36 \% 8 \mathrm{~h}$ after radiation (Figure 2C). In contrast, we only observed a slight increase in SW837 SCCs from 23 to 30\% (Figure 2C). This difference in cell cycle control, i.e. changes in the cell cycle distribution over time, was statistically significant $(P<0.05)$ between the negative control and the respective SCC populations in SW837. In HT-29, however, silencing of TCF4 did not alter cell cycle progression, i.e. both populations (SCCs and control) adequately arrested in $\mathrm{G}_{2} / \mathrm{M}$ phase $8 \mathrm{~h}$ after radiation (Figure $2 \mathrm{D}$ ), corresponding to a lack of radiosensitization.

Silencing of TCF4 impairs DNA double strand break repair in SW837 Insufficient DNA damage repair is an important component of radiation-induced cell killing $(17,18)$. To determine whether the radiosensitization following RNAi against TCF4 is indeed attributable to impaired DNA damage repair, we monitored the presence and persistence of phosphorylated histone $\mathrm{H} 2 \mathrm{AX}(\gamma \mathrm{H} 2 \mathrm{AX})$ foci $(17,18)$.

Regarding SW837, both populations (shNeg and SCCs) showed very few $\gamma \mathrm{H} 2 \mathrm{AX}$ foci in unirradiated cells and comparable levels of foci induction $15 \mathrm{~min}$ after irradiation at 2 Gy (exemplified in Figure 3A). Importantly, however, $24 \mathrm{~h}$ after irradiation, few foci remained in the non-silencing control, whereas the number of $\gamma \mathrm{H} 2 \mathrm{AX}$ foci in SW837 SCCs persisted at considerably higher levels (Figure 3A). This difference was statistically highly significant $(P<0.001$; Figure 3B). These foci can be considered 'residual', pointing to incomplete DNA double strand break (DSB) repair, which results in radiosensitivity $(19,20)$.

With respect to HT-29, both populations (shNeg and SCCs) showed minimal $\gamma \mathrm{H} 2 \mathrm{AX}$ foci in unirradiated cells and similar induction of foci 15 min after irradiation at 2 Gy (exemplified in Figure 3C). In striking contrast to SW837, both HT-29 populations exhibited an equally low number of $\gamma \mathrm{H} 2 \mathrm{AX}$ foci $24 \mathrm{~h}$ after irradiation (Figure $3 \mathrm{C}$ and D). These data support the notion that silencing of TCF4 leads to a significant impairment of DNA DSB repair in SW837, but not in HT-29.

TCF reporter activity determines radiosensitization in a $\beta$-catenin independent manner

TCF4 is a key transcription factor of canonical Wnt signaling (6-9). We therefore speculated that, despite comparable baseline protein expression levels of TCF4 in SW837 and HT-29, differences in the transcriptional activity might have caused the heterogeneous sensitivity of these cell lines to irradiation upon exposure to RNAi against TCF4. Using the TOP-FLASH/FOP-FLASH reporter assay, we established higher basal reporter activity for wild-type SW837 cells (TOP/ FOP: 6.9) than for wild-type HT-29 cells (TOP/FOP: 1.6). This difference was statistically significant $(P<0.01$; Figure 4A).

TCF4 is a binding partner of $\beta$-catenin, as both mediate the effects of canonical Wnt signaling. Notably, overexpression of mutated $\beta$-catenin (S33Y), which activates TCFs but cannot be inactivated, caused a $>10$-fold higher increase in reporter activity in wild-type SW837 cells (TOP/FOP: 34.3) than in wild-type HT-29 cells (TOP/ FOP: $2.9 ; P<0.001)$

Next, we analyzed the nuclear and cytosolic levels of $\beta$-catenin. Wild-type SW837 and HT-29 cells exhibited similar protein levels of both nuclear and cytosolic $\beta$-catenin (Figure 4B). These results suggest that radiosensitization following silencing of TCF4 is determined by TCF transcriptional activity but independent of $\beta$-catenin activity.

\section{Deregulation of Wnt/TCF4 signaling in SW837}

Finally, to demonstrate that silencing of TCF4 results in a transcriptional deregulation of Wnt/TCF4 signaling in SW837, but not in HT29 , we measured the expression levels of selected target genes (2123). Using real-time PCR, we observed a considerable deregulation of $C C N D 1, D K K 1$ and $M Y C$ in SW837 (Figure 5), with average foldchanges of 2.4 (CCND1, upregulated following silencing of TCF4), 18.4 (DKK1, downregulated) and 2.7 (MYC, downregulated). Notably, in HT-29, these downstream target genes either showed no prominent deregulation (CCND1; Figure 5) or their deregulation was inconsistent compared with SW837 (DKK and MYC; Figure 5). Collectively, these results demonstrate that RNAi against TCF4 resulted in a transcriptional deregulation of Wnt/TCF4 signaling in SW837, which was 
A

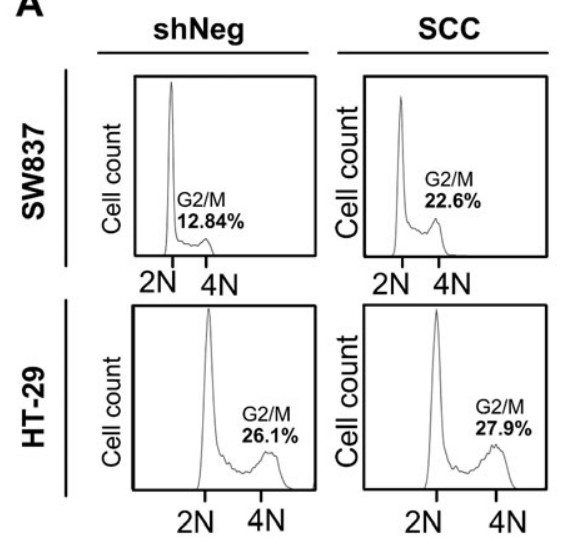

C

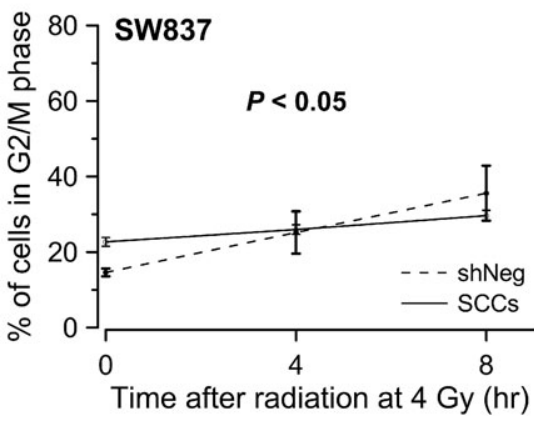

B

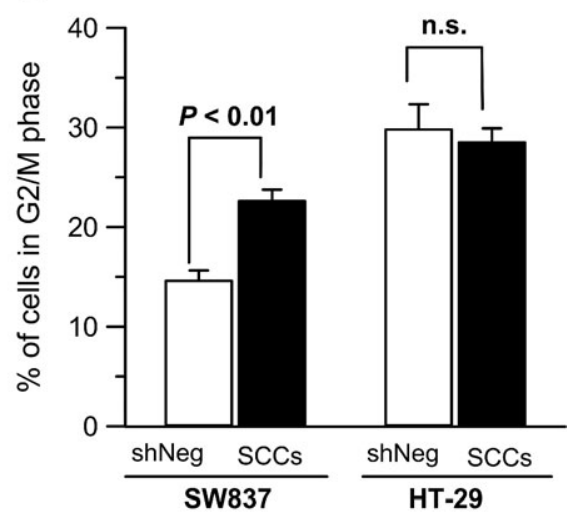

D

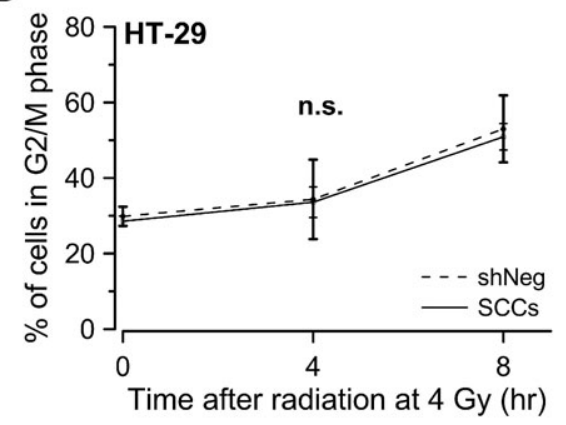

Fig. 2. Silencing of TCF4 in SW837 induces a $\mathrm{G}_{2} / \mathrm{M}$ arrest and impairs cell cycle control after radiation. (A) Representative cell cycle analysis of unirradiated tumor cells. (B) Compared with the non-silencing control, unirradiated SW837 SCCs exhibited a significantly higher fraction of cells in the radiosensitive $\mathrm{G}_{2} / \mathrm{M}$ phase $(P<0.01)$, whereas silencing of TCF4 in HT-29 did not alter cell cycle distribution. There was no difference in cell cycle distribution/progression between unirradiated shTCF4 SCCs and the respective non-silencing controls (data not shown). (C) Cell cycle analyses were also performed after irradiation. In the SW837 non-silencing control, the fraction of cells in $\mathrm{G}_{2} / \mathrm{M}$ phase significantly increased 4 and $8 \mathrm{~h}$ after irradiation at $4 \mathrm{~Gy}(P<0.05)$. In contrast, there was only a slight increase in SW837 SCCs, indicating an impaired ability of these SCCs to adequately halt cell cycle progression after irradiation. (D) Irradiation of both nonsilencing control and SCCs in HT-29 did not alter cell cycle progression. Data are presented as mean of at least three independent experiments \pm standard error of the mean.

associated with a significant sensitization to clinically relevant doses of X-rays.

\section{Discussion}

Resistance to preoperative chemoradiotherapy represents a major clinical problem in the treatment of rectal cancer. Consequently, the identification of novel therapeutic targets whose modification could be harnessed to sensitize a priori-resistant tumors to radiation is exceedingly important. Our earlier studies showed that the Wnt transcription factor TCF4 was overexpressed in primary rectal cancers that were resistant to preoperative chemoradiotherapy (5). The fact that Wnt signaling has not been previously associated with treatment resistance prompted us to explore whether this finding is functionally relevant. We now report that the Wnt transcription factor TCF4 mediates resistance to treatment with (chemo-) radiotherapy.

We first observed that TCF4 expression levels also correlated with (chemo-) radioresistance in CRC cell lines (Supplementary Figure $\mathrm{S} 1 \mathrm{~B}$ is available at Carcinogenesis Online). In order to explore the mechanistic basis of this correlation, we silenced TCF4 using RNA interference and measured the phenotypic effects. Indeed, silencing of TCF4 considerably increased sensitivity of SW480 and SW837 to clinically relevant doses of X-rays (Figure 1B, Supplementary Figure $\mathrm{S} 2$ is available at Carcinogenesis Online). However, this response was not uniform: the cell line HT-29 remained at resistance levels observed before silencing TCF4. A similar divergence became apparent when wild-type cell lines were treated with irradiation. In SW837 and
SW480, TCF4 protein expression levels increased in response to treatment with $6 \mathrm{~Gy}$ of X-rays, whereas the expression of TCF4 was unchanged in HT-29 (Supplementary Figure S3 is available at Carcinogenesis Online). This suggests that TCF4 plays different roles in these cell lines in mediating the response to irradiation.

To further clarify the functional mechanism of this increased sensitivity of SW837 after TCF4 depletion, we performed cell cycle measurements. Silencing of TCF4 was paralleled by an increased fraction of cells in the $\mathrm{G}_{2} / \mathrm{M}$ phase of the cell cycle at the time of irradiation ( $0 \mathrm{~h}$; Figure $2 \mathrm{~A}$ and $\mathrm{B})$. This phase is known for increased vulnerability to radiation-induced DNA damage (15). Of note, there was no change in cell cycle distribution upon silencing of TCF4 in HT-29, entirely consistent with its unchanged radiation response.

Exposure of cells to radiation per se leads to an arrest of cells in $\mathrm{G}_{2}$ / $\mathrm{M}$ phase, allowing time for DNA damage repair (16). In SW837, however, the $\mathrm{G}_{2} / \mathrm{M}$ arrest after irradiation ( 4 and $8 \mathrm{~h}$ ) was significantly less pronounced after silencing of TCF4 (Figure 2C). This impaired ability of the SW837 SCCs to halt cell cycle progression after irradiation was associated with a high number of persisting $\gamma \mathrm{H} 2 \mathrm{AX}$ foci (Figure 3A and B), which accumulate at sites of unrepaired DNA (17). These residual foci in SW837 SCCs suggest a compromised DNA DSB repair as an explanation for the increased radiosensitivity $(19,20)$. In other words, these SCCs may re-enter the cell cycle with persistent DNA DSBs, which would be consistent with an increased radiosensitivity $(24,25)$. In contrast, radiation-induced cell cycle arrest was not affected by silencing of TCF4 in HT-29 (Figure 2D), and the amount of $\gamma \mathrm{H} 2 \mathrm{AX}$ foci returned to near baseline levels after $24 \mathrm{~h}$ 
A
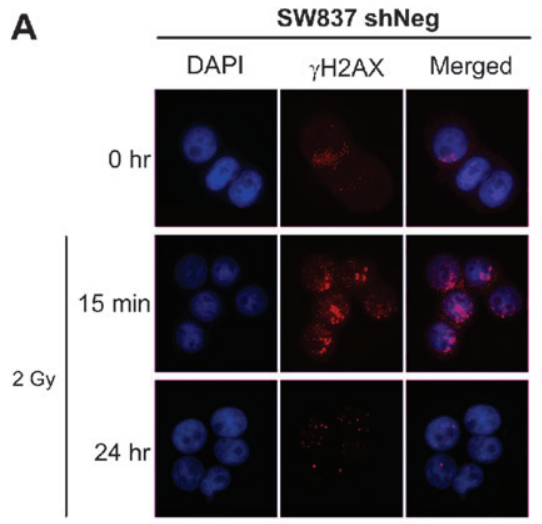

C
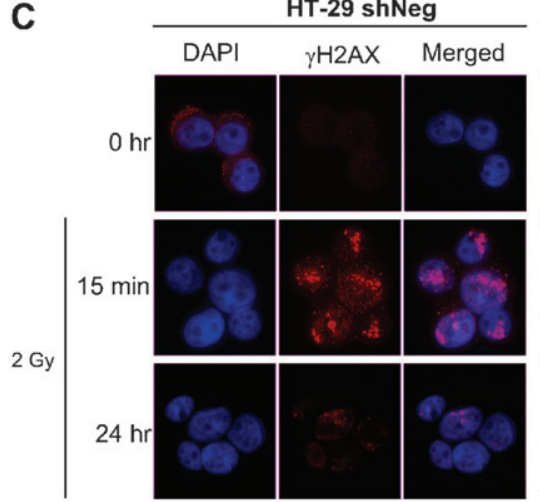

SW837 ShRNA_1 SCC 1
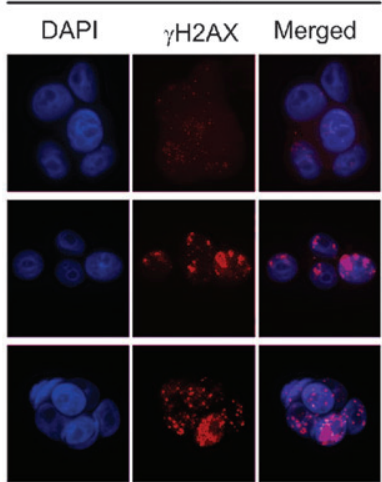

HT-29 ShRNA_1 SCC 1
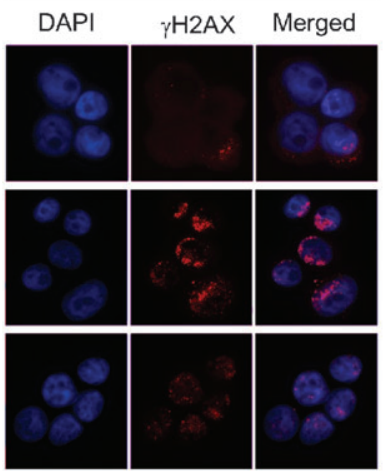

B

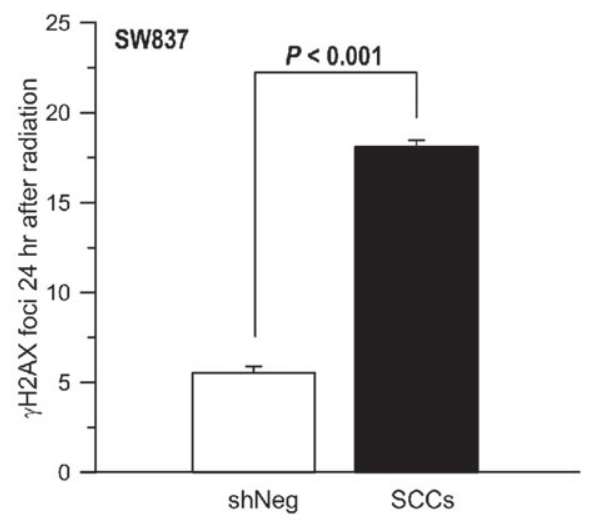

D

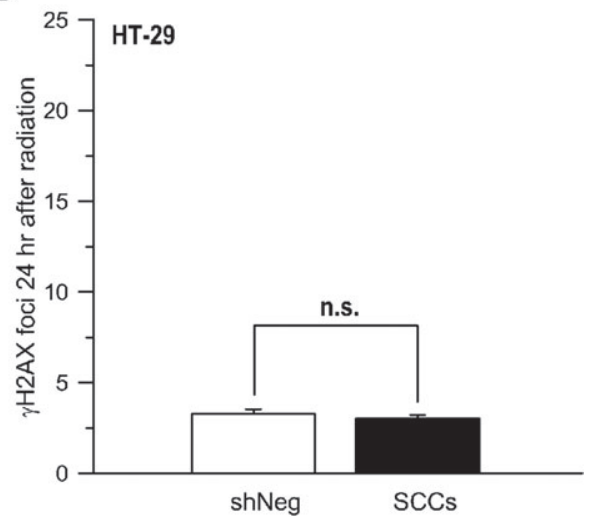

Fig. 3. Impaired radiation-induced DNA DSB repair in SW837 as indicator of increased radiosensitivity. (A) Representative experiment for SW837. Both populations (negative control and SCC) showed very few phosphorylated histone $\mathrm{H} 2 \mathrm{AX}(\gamma \mathrm{H} 2 \mathrm{AX})$ foci at the time of radiation and comparable induction of foci 15 min after irradiation at $2 \mathrm{~Gy}$. Twenty-four hours after irradiation, multiple $\gamma \mathrm{H} 2 \mathrm{AX}$ foci were present in the SCCs, whereas considerably fewer foci remained in the non-silencing control. (B) On average, there were highly significantly more $\gamma \mathrm{H} 2 \mathrm{AX}$ foci in SW837 SCCs $24 \mathrm{~h}$ after irradiation compared with shNeg $(P<0.001)$. (C) Representative experiment for HT-29. Both populations (negative control and SCC) showed very few $\gamma \mathrm{H} 2 \mathrm{AX}$ foci at the time of radiation, and exhibited a comparable induction of foci $15 \mathrm{~min}$ and $24 \mathrm{~h}$ after after irradiation at $2 \mathrm{~Gy}$. (D) In stark contrast to SW837, there was a similar level of $\gamma \mathrm{H} 2 \mathrm{AX}$ foci in negative control and HT-29 SCCs $24 \mathrm{~h}$ after irradiation. Data are presented as mean of three independent experiments \pm standard error of the mean.
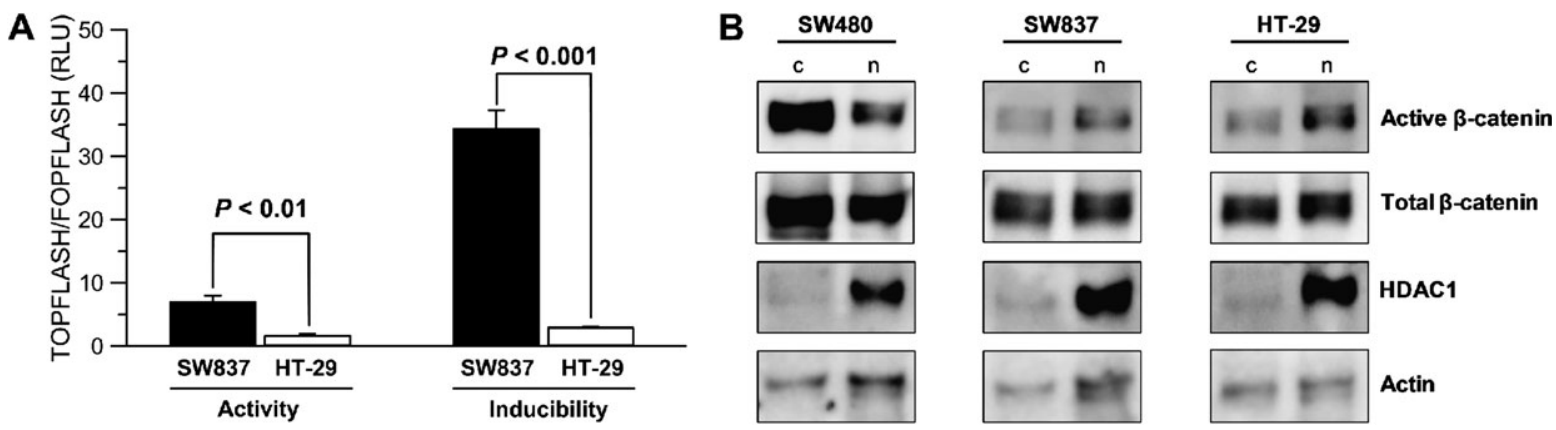

Fig. 4. Transcriptional activity of TCF determines radioresistance in SW837 in a $\beta$-catenin independent manner. (A) Normalized luciferase measurements. We established higher basal TCF reporter activity for wild-type SW837 cells (specific TOP-FLASH over non-specific FOP-FLASH activity: 6.9) than for wild-type HT-29 cells (TOP/FOP: 1.6; $P<0.01$ ). Overexpression of mutated $\beta$-catenin (S33Y), which binds to TCFs and cannot be inactivated, caused a $>10$-fold higher increase in reporter activity in SW837 (TOP/FOP: 34.3) than HT-29 (TOP/FOP: 2.9; $P<0.001$ ). Data are presented as mean of three independent experiments \pm standard error of the mean. (B) Based on western blot analysis, SW837 and HT-29 show comparable nuclear and cytosolic expression levels of both active (phosphorylated) and total $\beta$-catenin.

regardless of the presence of TCF4 (Figure 3C and D). Taken together, TCF4 seems to play an important role in regulating both cell cycle and DNA damage repair in a subset of CRC cells.

It is important to note that although connections between Wnt signaling and cell cycle regulation have been postulated $(26,27)$, only limited mechanistic details in support of the interplay between the two processes have been reported $(26,27)$. Interestingly, van de Wetering et al. (28) previously observed that inhibition of TCF4 activity in LS174T (wild-type p53 protein) and in DLD-1 (mutant p53 protein) using overexpression of a dominant-negative TCF4 protein mediated a $G_{1}$ arrest. This discrepancy with our observations could have been because of two reasons. Firstly, these authors have used a method that completely diminishes TCF4 protein levels, whereas, in our experiments, up to $10-20 \%$ of TCF4 protein remained following RNAi 

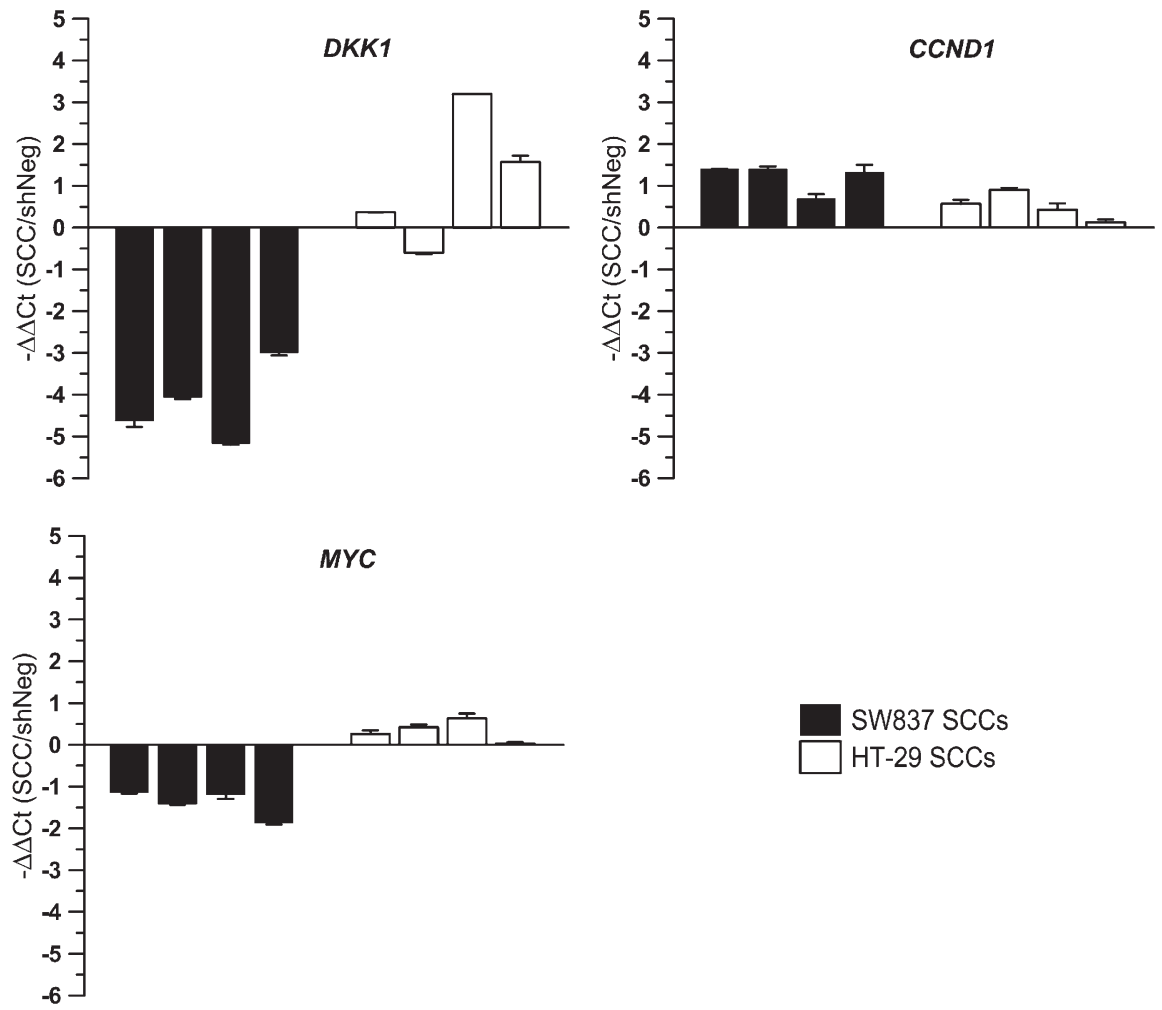

SW837 SCCs HT-29 SCCs

Fig. 5. Silencing of TCF4 results in a transcriptional deregulation of Wnt/TCF4 signaling in SW837. Silencing of TCF4 in SW837 (black) leads to a transcriptional deregulation of the Wnt/TCF4 target genes MYC (downregulated, average fold-change of 2.7), Cyclin D1 (upregulated, average fold-change of 2.4) and $D K K 1$ (downregulated, average fold-change of 18.4), whereas neither a prominent or consistent deregulation was observed in HT-29 (white). Plotted are the normalized expression levels of TCF4 in four SSCs relative to the negative control shNeg $(-\Delta \Delta C \mathrm{t})$. Data are presented as mean \pm standard error of the mean.

exposure (Figure 1A). Secondly, van de Wetering et al. analyzed CRC cell lines that were mismatch repair deficient. Nevertheless, our observation that RNAi against TCF4 resulted in significant changes in cell cycle distribution and an impaired ability to adequately halt cell cycle progression in response to irradiation adds weight to the growing body of evidence that the cell cycle machinery and Wnt signaling are functionally linked.

TCF4 represents a key downstream effector of canonical Wnt signaling (6-8). We therefore speculated that the diverse responses of SW837 and HT-29 may depend on varying transcriptional activities of TCF4. Indeed, unstimulated baseline levels of TCF reporter activity were higher in SW837 compared with HT-29 (Figure 4A). Moreover, reporter activity in SW837 increased dramatically upon overexpression of a mutated $\beta$-catenin protein (S33Y), which leads to constitutive $\mathrm{TCF} / \beta$-catenin activity, while there was only a slight increase in HT-29 (Figure 4A). At first glance, these results would indicate that SW837 is much more responsive to $\beta$-catenin binding than HT-29. Interestingly, however, we observed comparable nuclear and cytosolic levels of $\beta$-catenin in SW837 and HT-29 (Figure 4B), suggesting that the observed effect is $\beta$-catenin independent. In this context, recent observations demonstrate that lymphoid enhancer-binding factor/TCF family members do not exclusively confer canonical $\mathrm{Wnt} / \beta$-catenin signaling but also function as transcription factors in an alternative, $\beta$-catenin independent manner (29-32), and, presumably, in $\beta$-catenin-independent Wnt signaling (33-35).

Finally, we observed a transcriptional deregulation of the Wnt/ TCF4 target genes CCND1, DKK1 and MYC in SW837 SCCs, but not in HT-29 SCCs (Figure 5). Surprisingly, DKK1 expression decreased upon silencing of TCF4 in SW837 (Figure 5). At a first glance, this seems counterintuitive because $D K K 1$, a putative Wnt antagonist, represents a tumor suppressor gene (36). The same holds true for the observed upregulation of CCDN1. Cyclin D1 represents a core component of the cell cycle machinery $(37,38)$ and has been very recently implicated in DNA repair (39). Considering the increased fraction of SW837 cells in $\mathrm{G}_{2} / \mathrm{M}$ phase following RNAi against TCF4, this upregulation is unexpected and may be attributed to the fact that stable SCC populations have been used in this study. These clones have been cultured for longer periods of time, potentially allowing time to counterbalance certain consequences of diminished expression of the transcription factor TCF4. Nevertheless, the transcriptional deregulation of Wnt signaling, irrespective of the directionality of deregulation, is consistent with the prevailing interpretation that disturbing the net cellular homeostasis of the Wnt pathway constitutes a critical step toward a tumor promoting function (40).

Although we are the first to report that inhibition of Wnt/TCF4 signaling sensitizes CRC cell lines to radiation and chemoradiotherapy, preliminary evidence from other model systems is consistent with these findings. Firstly, our own group recently reported that Wnt signaling pathway genes were significantly over-represented within a gene expression signature for in vitro sensitivity of CRC cells lines to 5-FU-based chemoradiotherapy (10). Secondly, based on the fact that Wnt signaling has been implicated in regulating the behavior of both somatic stem cells and tumor-initiating 'cancer stem' cells $(41,42)$, other authors demonstrated that Wnt signaling mediates radiation resistance of mammary progenitor cells in mice $(43,44)$. Thirdly, Flahaut et al. (45) reported that the frizzled-1 Wnt receptor FZD1 mediates chemoresistance in neuroblastoma cell lines through MDR1, whereas Shou et al. observed that overexpression of DKK1 sensitized brain tumor cells to apoptosis upon treatment with DNAalkylating agents (46). And fourthly, Kriegl et al. (47) recently demonstrated that TCF4 expression, based on immunohistochemical analyses of primary CRCs, was a negative prognostic factor associated with shorter overall survival.

In summary, we provide the first evidence that the Wnt transcription factor TCF4 is intricately involved in mediating resistance of $\mathrm{CRC}$ cell lines and primary rectal cancers to radiation and 


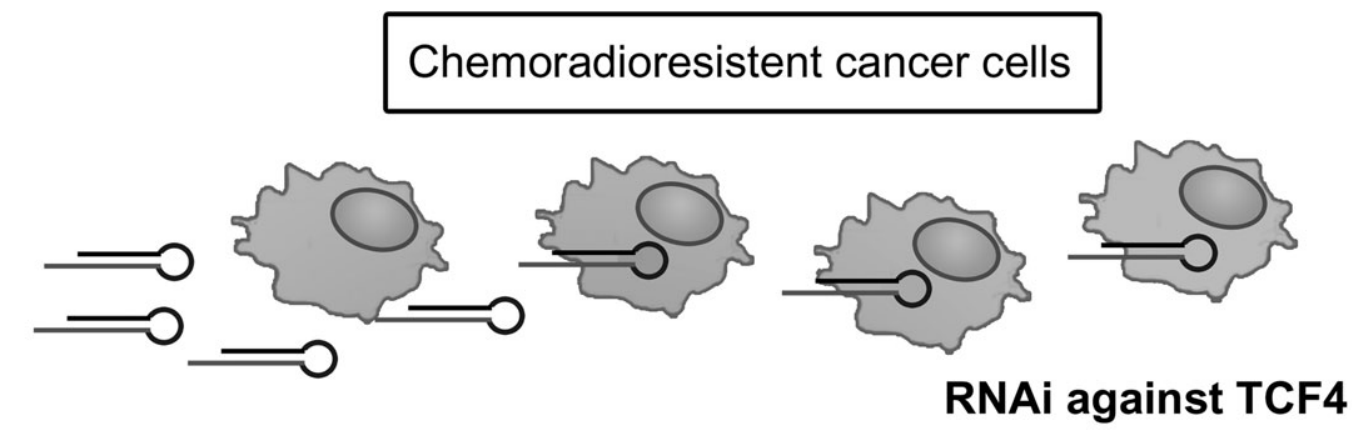

\section{TCF reporter activity}
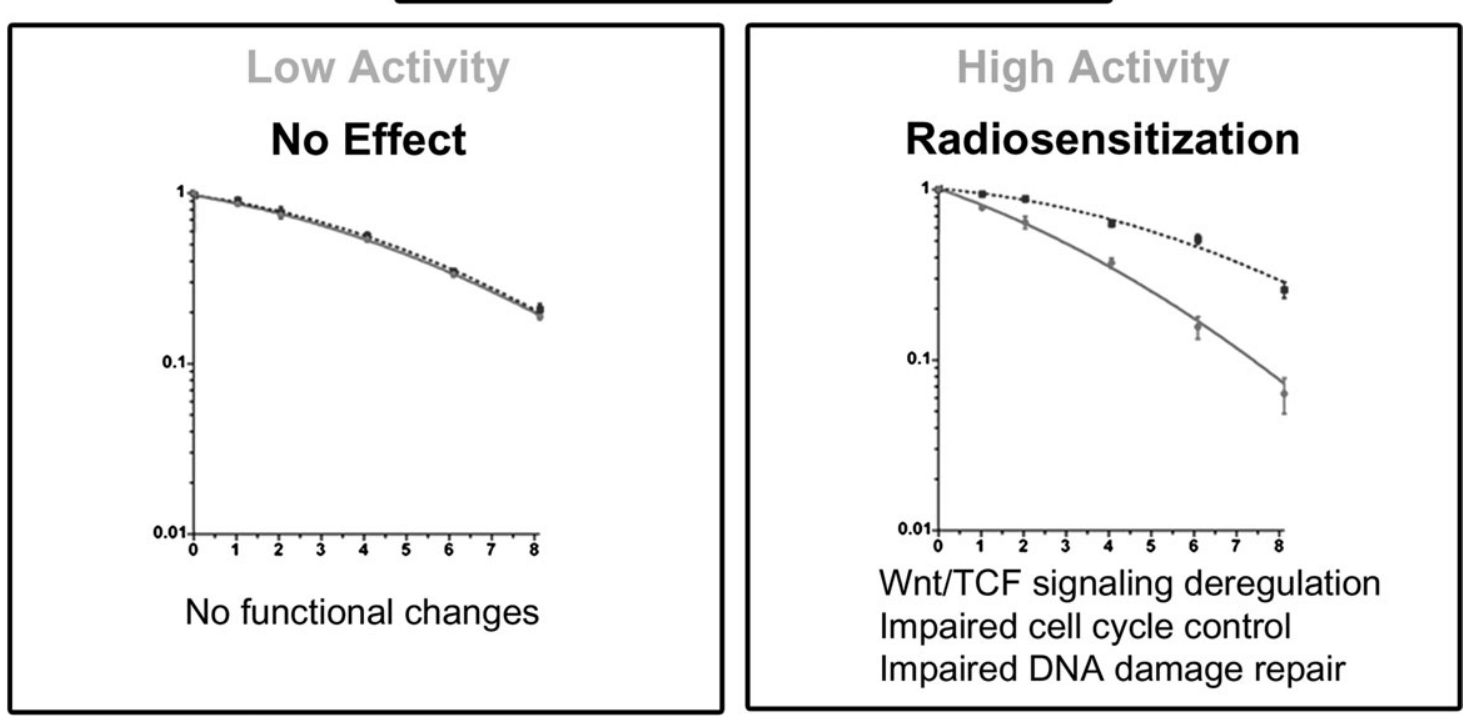

Fig. 6. Mechanistic model for the novel role of Wnt/TCF4 signaling. Mechanistic model depicting a novel mechanism through which the Wnt transcription factor TCF4 mediates resistance of CRC cells to chemoradiotherapy.

chemoradiotherapy. TCF4 therefore represents a promising molecular target to sensitize a priori-resistant rectal cancers to irradiation. Although we began to decipher the underlying cellular mechanisms (Figure 6), future studies will ultimately elucidate the downstream effects and regulation of TCF4 that mediate this important phenomenon, and they will further characterize the putative $\beta$-catenin independency of this novel role of TCF4. If further validated, Wnt/TCF4 signaling inhibition may represent an effective strategy to increase the fraction of patients that respond to multimodal treatment and improve overall survival.

\section{Supplementary material}

Supplementary Tables S1-S4 and Figures S1-S4 can be found at http://carcin.oxfordjournals.org/

\section{Funding}

Deutsche Forschungsgemeinschaft (KFO 179).

\section{Acknowledgements}

The authors are grateful to Jessica Eggert, Antje Schneeberg, and Birte Roesler for excellent technical support. We thank Felix Brembeck and Maria Wiese for assistance with reporter assays, Markus Löbrich and Julia Krasnyanska for help with $\gamma \mathrm{H} 2 \mathrm{AX}$ experiments, Michael Klintschar for short-tandem repeat analysis and Holger Bastians for helpful discussions and critically reading our manuscript. Reporter plasmids were kindly provided by Silke Kaulfu $\beta$.

Conflict of Interest Statement: None declared.

\section{References}

1. Glimelius,B. et al. (2009) Rectal cancer: ESMO clinical recommendations for diagnosis, treatment and follow-up. Ann. Oncol., 20 (Suppl. 4), 54-56.

2. Sauer,R. et al. (2004) Preoperative versus postoperative chemoradiotherapy for rectal cancer. N. Engl. J. Med., 351, 1731-1740.

3. Cunningham,D. et al. (2010) Colorectal cancer. Lancet, 375, 1030-1047.

4. Kuremsky,J.G. et al. (2009) Biomarkers for response to neoadjuvant chemoradiation for rectal cancer. Int. J. Radiat. Oncol. Biol. Phys., 74, 673688.

5. Ghadimi,B.M. et al. (2005) Effectiveness of gene expression profiling for response prediction of rectal adenocarcinomas to preoperative chemoradiotherapy. J. Clin. Oncol., 23, 1826-1838.

6. Moon,R.T. et al. (2004) WNT and beta-catenin signalling: diseases and therapies. Nat. Rev. Genet., 5, 691-701.

7. Clevers,H. (2006) Wnt/beta-catenin signaling in development and disease. Cell, 127, 469-480.

8. Klaus,A. et al. (2008) Wnt signalling and its impact on development and cancer. Nat. Rev. Cancer, 8, 387-398.

9. Arce,L. et al. (2006) Diversity of LEF/TCF action in development and disease. Oncogene, 25, 7492-7504. 
10. Spitzner,M. et al. (2010) A gene expression signature for chemoradiosensitivity of colorectal cancer cells. Int. J. Radiat. Oncol. Biol. Phys., 78, 1184-1192.

11. Grade,M. et al. (2011) A genomic strategy for the functional validation of colorectal cancer genes identifies potential therapeutic targets. Int. J. Cancer, 128, 1069-1079.

12. Livak,K.J. et al. (2001) Analysis of relative gene expression data using realtime quantitative PCR and the 2(-Delta Delta C(T)) Method. Methods, 25, 402-408.

13. Rodrigues,N.R. et al. (1990) p53 mutations in colorectal cancer. Proc. Natl Acad. Sci. USA, 87, 7555-7559.

14. Liu,Y. et al. (2006) Analysis of P53 mutations and their expression in 56 colorectal cancer cell lines. Proc. Natl Acad. Sci. USA, 103, 976-981.

15. Seiwert,T.Y. et al. (2007) The concurrent chemoradiation paradigm-general principles. Nat. Clin. Pract. Oncol., 4, 86-100.

16. O'Driscoll,M. et al. (2006) The role of double-strand break repair-insights from human genetics. Nat. Rev. Genet., 7, 45-54.

17. Lobrich,M. et al. (2010) gammaH2AX foci analysis for monitoring DNA double-strand break repair: strengths, limitations and optimization. Cell Cycle, 9, 662-669.

18. Bonner,W.M. et al. (2008) GammaH2AX and cancer. Nat. Rev. Cancer, 8 , 957-967.

19. Rogakou,E.P. et al. (1999) Megabase chromatin domains involved in DNA double-strand breaks in vivo. J. Cell Biol., 146, 905-916.

20. Dikomey,E. et al. (1998) Correlation between cellular radiosensitivity and non-repaired double-strand breaks studied in nine mammalian cell lines. Int. J. Radiat. Biol., 73, 269-278.

21. He,T.C. et al. (1998) Identification of c-MYC as a target of the APC pathway. Science, 281, 1509-1512.

22. Tetsu,O. et al. (1999) Beta-catenin regulates expression of cyclin D1 in colon carcinoma cells. Nature, 398, 422-426.

23. Niida,A. et al. (2004) DKK1, a negative regulator of Wnt signaling, is a target of the beta-catenin/TCF pathway. Oncogene, 23, 8520-8526.

24. Fingert,H.J. et al. (1986) Cytotoxic, cell cycle, and chromosomal effects of methylxanthines in human tumor cells treated with alkylating agents. Cancer Res., 46, 2463-2467.

25. Hartwell,L.H. et al. (1994) Cell cycle control and cancer. Science, 266, 1821-1828.

26. Davidson, G. et al. (2009) Cell cycle control of wnt receptor activation. Dev. Cell, 17, 788-799.

27. Davidson,G. et al. (2010) Emerging links between CDK cell cycle regulators and Wnt signaling. Trends Cell Biol., 20, 453-460.

28. van de Wetering,M. et al. (2002) The beta-catenin/TCF-4 complex imposes a crypt progenitor phenotype on colorectal cancer cells. Cell, 111, 241-250.

29. Giese,K. et al. (1993) LEF-1 contains an activation domain that stimulates transcription only in a specific context of factor-binding sites. EMBO J., 12, $4667-4676$.
30. Love,J.J. et al. (1995) Structural basis for DNA bending by the architectural transcription factor LEF-1. Nature, 376, 791-795.

31. Giese,K. et al. (1997) Functional analysis of DNA bending and unwinding by the high mobility group domain of LEF-1. Proc. Natl Acad. Sci. USA, 94, 12845-12850.

32. Waterman,M.L. (2004) Lymphoid enhancer factor/T cell factor expression in colorectal cancer. Cancer Metastasis Rev., 23, 41-52.

33. Klemm,F. et al. (2011) Beta-catenin-independent WNT signaling in basallike breast cancer and brain metastasis. Carcinogenesis, 32, 434-442.

34. Kikuchi,A. et al. (2008) Tumor formation due to abnormalities in the betacatenin-independent pathway of Wnt signaling. Cancer Sci., 99, 202-208.

35. Sato,A. et al. (2010) Wnt5a regulates distinct signalling pathways by binding to Frizzled2. EMBO J., 29, 41-54.

36. Gonzalez-Sancho,J.M. et al. (2005) The Wnt antagonist DICKKOPF-1 gene is a downstream target of beta-catenin/TCF and is downregulated in human colon cancer. Oncogene, 24, 1098-1103.

37. Kim,J.K. et al. (2009) Nuclear cyclin D1: an oncogenic driver in human cancer. J. Cell Physiol., 220, 292-296.

38. Lamb,J. et al. (2003) Cyclin D1 and molecular chaperones: implications for tumorigenesis. Cell Cycle, 2, 525-527.

39. Jirawatnotai,S. et al. (2011) A function for cyclin D1 in DNA repair uncovered by protein interactome analyses in human cancers. Nature, $\mathbf{4 7 4}$, 230-234.

40.Lucero,O.M. et al. (2010) A re-evaluation of the "oncogenic" nature of Wnt/beta-catenin signaling in melanoma and other cancers. Curr. Oncol. Rep., 12, 314-318.

41. Reya,T. et al. (2005) Wnt signalling in stem cells and cancer. Nature, 434 843-850.

42. Fodde, R. et al. (2007) Wnt/beta-catenin signaling in cancer stemness and malignant behavior. Curr. Opin. Cell Biol., 19, 150-158.

43. Woodward,W.A. et al. (2007) WNT/beta-catenin mediates radiation resistance of mouse mammary progenitor cells. Proc. Natl Acad. Sci. USA, 104, $618-623$.

44.Zhang,M. et al. (2009) Selective targeting of radiation-resistant tumorinitiating cells. Proc. Natl Acad. Sci. USA, 107, 3522-3527.

45. Flahaut,M. et al. (2009) The Wnt receptor FZD1 mediates chemoresistance in neuroblastoma through activation of the Wnt/beta-catenin pathway. Oncogene, 28, 2245-2256.

46. Shou,J. et al. (2002) Human Dkk-1, a gene encoding a Wnt antagonist, responds to DNA damage and its overexpression sensitizes brain tumor cells to apoptosis following alkylation damage of DNA. Oncogene, 21 , 878-889.

47. Kriegl,L. et al. (2010) LEF-1 and TCF4 expression correlate inversely with survival in colorectal cancer. J. Transl. Med., 8, 123.

Received May 31, 2011; revised September 2, 2011; accepted October 2, 2011 
A)

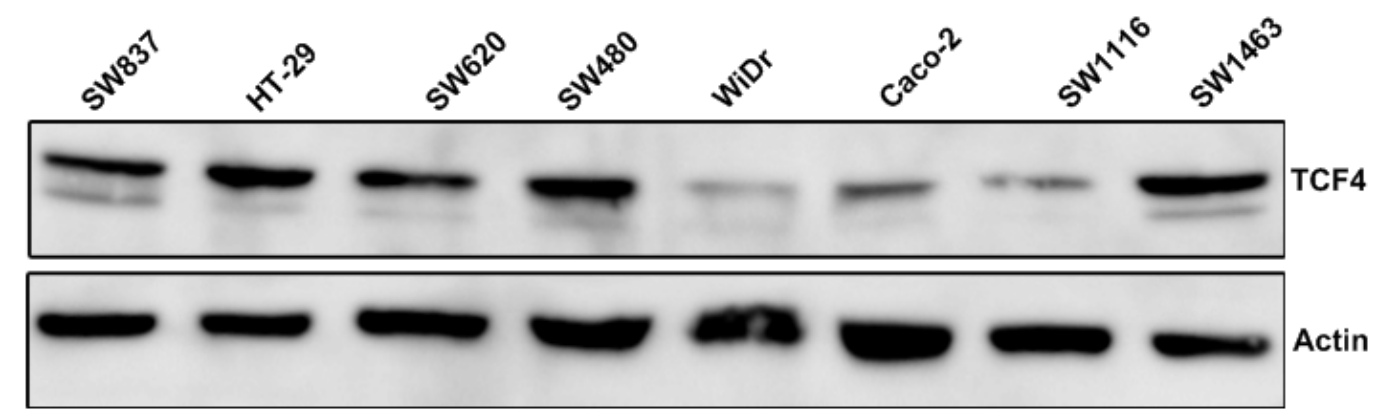

B)

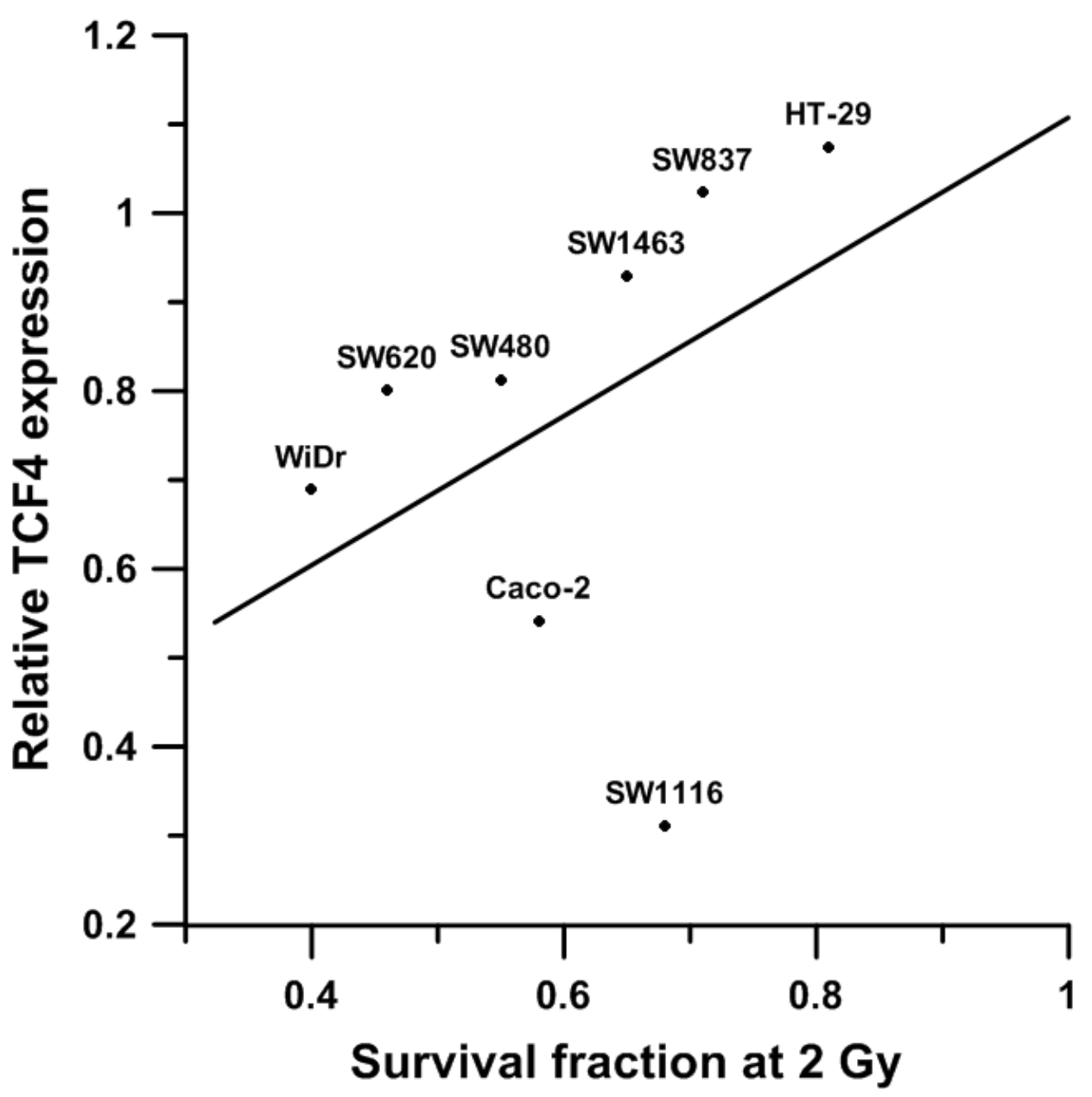

Figure S1. TCF4 Protein Expression Correlates Positively with Resistance of CRC cell lines to Chemoradiotherapy.

(A) Representative Western blot analysis of eight colorectal cancer cell lines. (B) TCF4 protein expression was compared to their respective in vitro sensitivities to 5-FU-based chemoradiotherapy. With the exception of Caco2 and SW1116, TCF4 expression was positively correlated with treatment resistance. Results are shown for one representative experiment. 

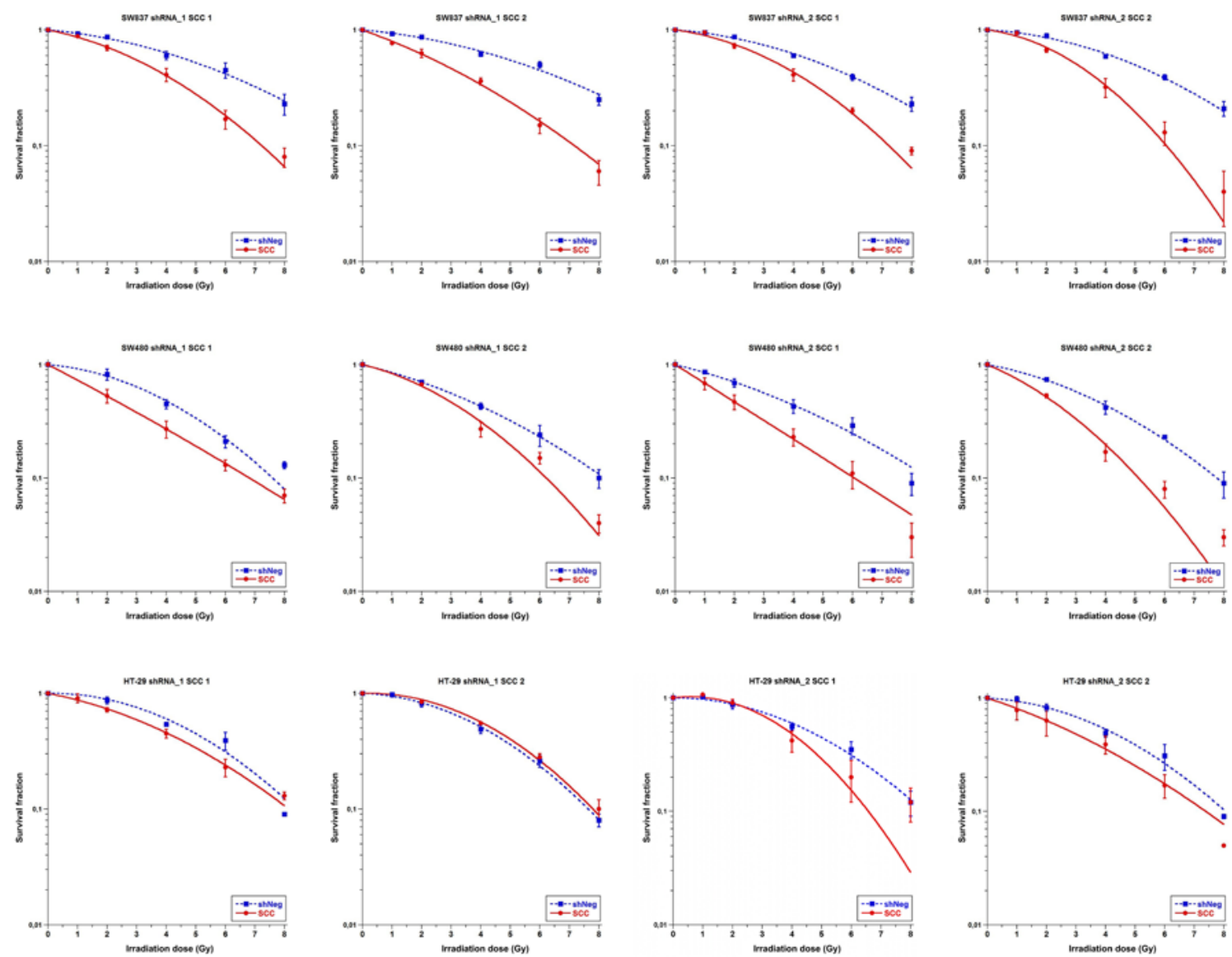

\section{Figure S2. Silencing of TCF4 Sensitizes SW837 and SW480 Cells to Irradiation}

Selected SCCs from SW837, SW480 and HT-29 were irradiated at clinically relevant doses of X-rays. A standard colony-forming assay demonstrated that silencing of TCF4 considerably increased the radiosensitivity of SW837 $\left(P<10^{-16}\right.$, multiple linear regression model) and SW480 $\left(P<10^{-16}\right)$, but not of HT-29 $(P=0.7)$. Data are presented as mean of three independent experiments \pm SEM. 
SW480

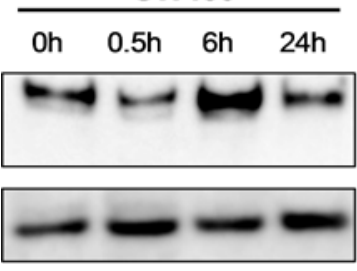

SW837

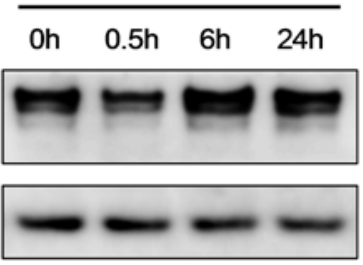

HT-29

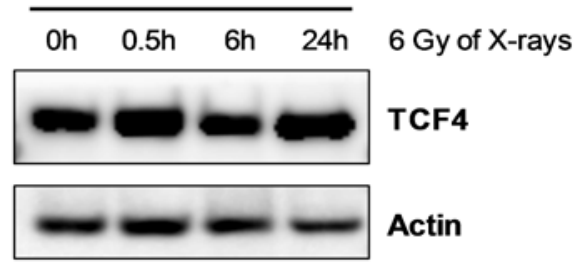

Figure S3: TCF4 expression increases in SW480 and SW837 in response to irradiation.

Representative Western blot analysis of CRC cell lines treated with 6 Gy of X-rays. Notably, in SW837 and SW480, TCF4 protein expression levels increased in response to radiation, whereas the expression of TCF4 was unchanged in HT-29. 

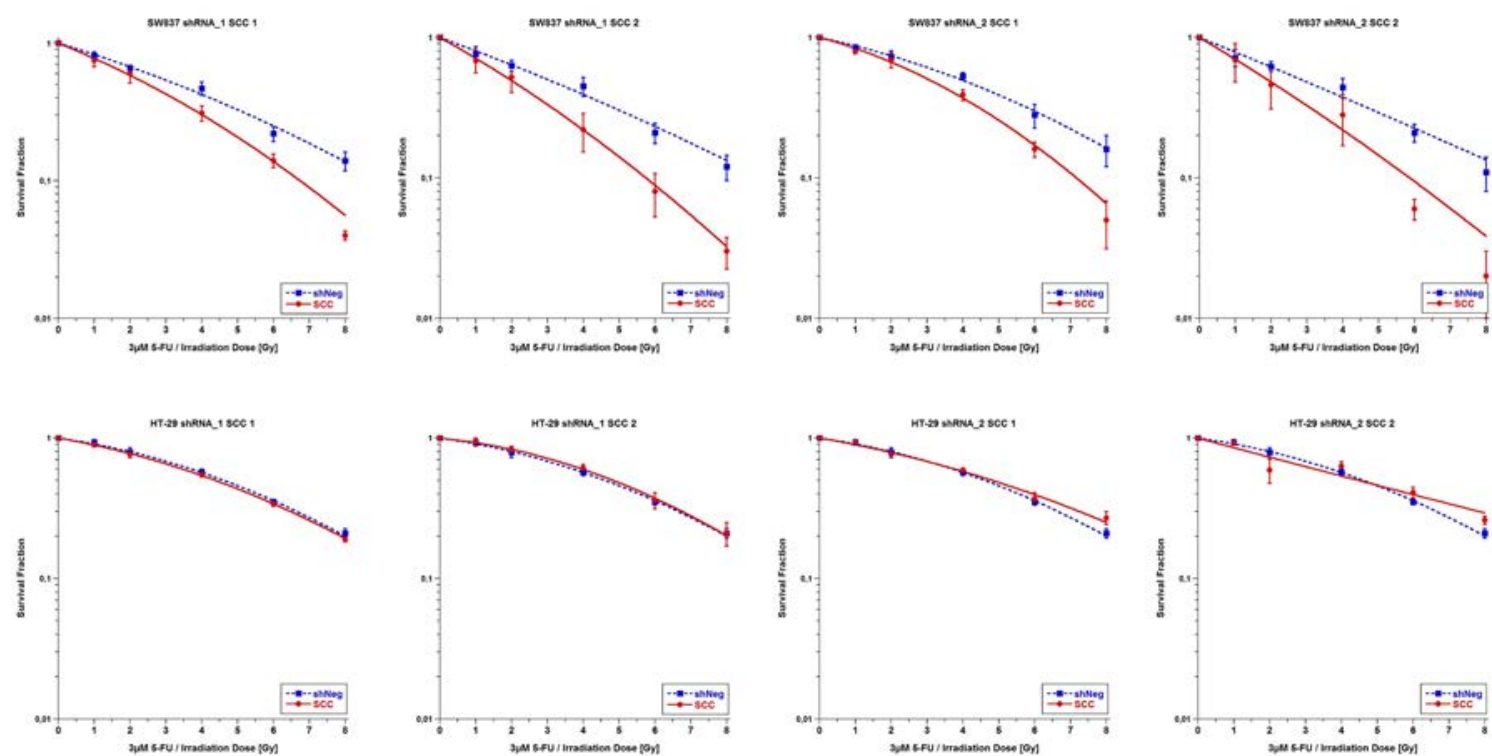

Figure S4. Silencing of TCF4 Sensitizes SW837 Cells to Chemoradiotherapy

Selected SCCs from SW837 and HT-29 were treated with $3 \mu \mathrm{M}$ of 5-FU and irradiated at clinically relevant doses of X-rays). A standard colony-forming assay demonstrated that silencing of TCF4 considerably increased the chemoradiosensitivity of SW837 ( $P<10^{-11}$, multiple linear regression model), but not of HT-29 $(P=0.7)$. Data are presented as mean of three independent experiments \pm SEM. 
Table S1

$\begin{array}{lll}\text { Cell Line } & \text { shRNA } & \text { Sequence } \\ \text { SW837 } & 1 & \text { TGCTGTTGACAGTGAGCGAGCACACATTGTCTCTAACAAATAGTGAAGCCACAGATGTATTTGTTAGAGACAATGTGTGCCTGCCTACTGCCTCGGA } \\ \text { SW837 } & 2 & \text { TGCTGTTGACAGTGAGCGACGAACCTATCTCCAGATGAAATAGTGAAGCCACAGATGTATTTCATCTGGAGATAGGTTCGGTGCCTACTGCCTCGGA } \\ \text { HT-29 } & 1 & \text { TGCTGTTGACAGTGAGCGAGCACACATTGTCTCTAACAAATAGTGAAGCCACAGATGTATTTGTTAGAGACAATGTGTGCCTGCCTACTGCCTCGGA } \\ \text { HT-29 } & 2 & \text { TGCTGTTGACAGTGAGCGAGCACACATTGTCTCTAACAAATAGTGAAGCCACAGATGTATTTGTTAGAGACAATGTGTGCCTGCCTACTGCCTCGGA } \\ \text { SW480 } & 1 & \\ \text { SW480 } & 2 & \end{array}$

Table S1. Target sequences of Expression Arrest ${ }^{\mathrm{TM}}$ lentiviral short-hairpin RNA constructs targeting TCF4.

Color Codes: mir-30 contextsenseloopantisense 
Table S2

\begin{tabular}{cccccc}
\hline Cell Line & TP53 Mutation* & Growth Medium & FBS (\%) & Doubling Time (hr) & CFA Growth Time (days) \\
\hline HT-29 & + & McCoy's & 10 & 22 & 8 \\
SW837 & + & L-15 & 10 & 64 & 21 \\
SW480 & + & L-15 & 10 & 32 & 10 \\
\hline
\end{tabular}

* Rodrigues et al. ProcNatlAcadSci USA 1990; Liu and Bodmer ProcNatlAcadSci U S A 2006

Table S2. Characteristics and experimental conditions. 
Table S3

\begin{tabular}{|c|c|c|c|c|c|c|c|c|}
\hline \multicolumn{9}{|c|}{ Radiation Therapy } \\
\hline SW480 & Negative Control & shRNA_1 SCC 1 & Negative Control & shRNA_1 SCC 2 & Negative Control & shRNA_2 SCC 1 & Negative Control & shRNA_2 SCC 2 \\
\hline$\alpha$ & 0.051 & 0.311 & 0.143 & 0.145 & 0.148 & 0.374 & 0.110 & 0.250 \\
\hline$\beta$ & 0.033 & 0.004 & 0.017 & 0.036 & 0.014 & 0.001 & 0.024 & 0.039 \\
\hline DMF $37 \%$ survival & \multicolumn{2}{|c|}{1.58} & \multicolumn{2}{|c|}{1.28} & \multicolumn{2}{|c|}{1.78} & \multicolumn{2}{|c|}{1.62} \\
\hline SW837 & Negative Control & shRNA_1 SCC 1 & Negative Control & shRNA_1 SCC 2 & Negative Control & shRNA_2 SCC 1 & Negative Control & shRNA_2SCC 2 \\
\hline$\alpha$ & 0.114 & 0.051 & 0.051 & 0.208 & 0.043 & 0.075 & 0.033 & 0.072 \\
\hline$\beta$ & 0.011 & 0.016 & 0.014 & 0.016 & 0.019 & 0.034 & 0.021 & 0.051 \\
\hline DMF 37\% survival & \multicolumn{2}{|c|}{1.60} & \multicolumn{2}{|c|}{1.90} & \multicolumn{2}{|c|}{1.43} & \multicolumn{2}{|c|}{1.70} \\
\hline HT29 & Negative Control & shRNA_1 SCC 1 & Negative Control & shRNA_1 SCC 2 & Negative Control & shRNA_2 SCC 1 & Negative Control & shRNA_2 SCC 2 \\
\hline$\alpha$ & -0.008 & 0.112 & 0.019 & -0.018 & -0.001 & -0.078 & 0.033 & 0.197 \\
\hline$\beta$ & 0.034 & 0.021 & 0.037 & 0.040 & 0.032 & 0.065 & 0.031 & 0.015 \\
\hline DMF $37 \%$ survival & \multicolumn{2}{|c|}{1.20} & \multicolumn{2}{|c|}{1.08} & \multicolumn{2}{|c|}{1.18} & \multicolumn{2}{|c|}{1.33} \\
\hline \multicolumn{9}{|c|}{ 5-FU based Chemoradiotherapy } \\
\hline
\end{tabular}

\begin{tabular}{|c|c|c|c|c|c|c|c|c|}
\hline SW837 & Negative Control & shRNA_1 SCC 1 & Negative Control & shRNA_1 SCC 2 & Negative Control & shRNA_2 SCC 1 & Negative Control & shRNA_2 SCC 2 \\
\hline$\alpha$ & 0.181 & 0.238 & 0.216 & 0.329 & 0.125 & 0.156 & 0.239 & 0.351 \\
\hline$\beta$ & 0.008 & 0.015 & 0.004 & 0.012 & 0.013 & 0.023 & 0.002 & 0.046 \\
\hline DMF 37\% survival & \multicolumn{2}{|c|}{1.32} & \multicolumn{2}{|c|}{1.59} & \multicolumn{2}{|c|}{1.35} & \multicolumn{2}{|c|}{1.54} \\
\hline HT29 & Negative Control & shRNA_1 SCC 1 & Negative Control & shRNA_1 SCC 2 & Negative Control & shRNA_2 SCC 1 & Negative Control & shRNA_2 SCC 2 \\
\hline$\alpha$ & 0.081 & 0.101 & 0.081 & 0.056 & 0.081 & 0.100 & 0.081 & 0.157 \\
\hline$\beta$ & 0.015 & 0.013 & 0.015 & 0.018 & 0.015 & 0.009 & 0.015 & 0.000 \\
\hline DMF 37\% survival & \multicolumn{2}{|c|}{1.05} & \multicolumn{2}{|c|}{1.02} & \multicolumn{2}{|c|}{1.07} & \multicolumn{2}{|c|}{1.08} \\
\hline
\end{tabular}

Table S3. Survival variables $\alpha$ and $\beta$ and DMFs 


\section{Table S4}

\begin{tabular}{cccc}
\hline Symbol & Accession Number & Forward Primer Sequence & Reverse Primer Sequence \\
\hline DKK1 & NM_012242 & CATCAGACTGTGCCTCAGGA & CCACAGTAACAACGCTGGAA \\
CCND1 & CM_053056 & & TGGGGTCCATGTTCTGCT \\
MYC & NM_002467 & CAAGCAGAGGAGCAAAAG & CGCACAAGAGTTCCGTAG \\
HPRT1 & NM_000194 & TGACACTGGCAAAACAATGCA & GGTCCTTTCACCAGCAAGCT \\
YWHAZ & NM_145690, NM_003406, & ACTTTTGGTACATTGTGGCTTCAAACAACT & CCGCCAGGACAAACCAGTAT \\
& NM_001135702, NM_001135701, & & \\
NM_001135700, NM_001135699 & & \\
\hline
\end{tabular}

Table S4. Primer sequences for real-time PCR analysis. 